\title{
Effect of gas compression on mining fire scenario in gaseous and dusty-gaseous environments
}

Anish Raman Calavay

Follow this and additional works at: https://researchrepository.wvu.edu/etd

\section{Recommended Citation}

Calavay, Anish Raman, "Effect of gas compression on mining fire scenario in gaseous and dusty-gaseous environments" (2015). Graduate Theses, Dissertations, and Problem Reports. 5299.

https://researchrepository.wvu.edu/etd/5299

This Thesis is protected by copyright and/or related rights. It has been brought to you by the The Research Repository @ WVU with permission from the rights-holder(s). You are free to use this Thesis in any way that is permitted by the copyright and related rights legislation that applies to your use. For other uses you must obtain permission from the rights-holder(s) directly, unless additional rights are indicated by a Creative Commons license in the record and/ or on the work itself. This Thesis has been accepted for inclusion in WVU Graduate Theses, Dissertations, and Problem Reports collection by an authorized administrator of The Research Repository @ WVU. For more information, please contact researchrepository@mail.wvu.edu. 


\title{
Effect of Gas Compression on Mining Fire Scenario in Gaseous and Dusty-Gaseous Environments
}

\author{
Anish Raman Calavay \\ Thesis submitted to the \\ Benjamin M. Statler College of Engineering and Mineral Resources \\ at \\ West Virginia University in Partial Fulfillment of the Requirements for the Degree of \\ Master of Science \\ in \\ Mechanical Engineering \\ V'yacheslav Akkerman, Ph.D., Chairperson Arvind \\ Thiruvengadam, Ph.D. \\ Patrick Browning Ph.D. \\ Department of Mechanical and Aerospace Engineering \\ Morgantown, West Virginia
}

(2015)

Keywords: laminar flames, fire safety; mining fire scenario; combustion instability; flame acceleration; detonation triggering; turbulent burning; dusty-gaseous combustion. 


\section{ABSTRACT}

Accidental gas and dust explosions constitute a tremendous hazard for personnel and equipment in industries dealing with flammable gases and explosive materials. Historically, the coal mine industry has one of the highest occupational fatality and injury rates, claiming hundreds of miners' lives every year. To reduce the risk of mining scenarios, a joint team of West Virginia University and Worcester Polytechnic Institute are developing a comprehensive analytical, computational and experimental platform that will eventually be able to quantify the probability of a fire initiation and/or a deflagration-to-detonation transition as well as the methodologies how to terminate or, at least, mitigate these disasters. Within the frame of this research, a predictive scenario of a methane-air fire in a dusty-gaseous environment of a mining passage is being developed. Among various mechanisms responsible for the flame acceleration such as combustion instability, turbulence, acoustics, and wall friction, the acceleration due to a fingershaped flame front plays a dominant role here, because this mechanism is scale-invariant and, thereby, Reynolds-independent. This finger-flame acceleration is very powerful, promoting the speed of the fire spreading by an order of magnitude. However, this acceleration scenario is limited in time: it is terminated as soon as the flame skirt contacts a passage wall. While the existing analytical formulation of this predictive scenario is based on the incompressible approximation, in this particular study, the effects of gas compressibility on the mining fire scenario are quantified by means of the analytical and computational endeavors. It is shown that gas compressibility generally moderates the flame acceleration, and the result depends on various thermal-chemical parameters. While the effect of compressibility is minor (say, providing a 3$5 \%$ reduction) for lean and rich methane-air pre mixtures, thereby justifying the incompressible formulation in that case, it appears significant (provides a reduction of 10-20\%) for nearstoichiometric methane-air combustion, and therefore should be incorporated into a rigorous formulation. Starting with gaseous fuels, the formulation is then extended to dusty-gaseous flows. Specifically, the effects of equivalence ratio and dust size/concentration on the flame characteristics, such as the flame speed and temperature, are systematically investigated. In this respect, combustible and inert dusts, as well as their mixture, are studied. 


\section{Acknowledgements}

The major part of this thesis would not come into being without several key individuals, to which I would express my gratitude and sincere appreciation.

Primarily, I would like to thank Dr. V'yacheslav Akkerman, who helped me to pursue my career in the MAE Department at WVU. Without his guidance and support I would never accomplished my goal of pursuing research at MAE. Also, I am grateful to my MS Committee members, namely, Dr. Arvind Thiruvengadam, who has been a valuable mentor for me even beyond academics, and Dr. Patrick Browning, for his gracious support.

Furthermore, I would like to express my sincere thanks to Dr. Ali Rangwala of Worcester Polytechnic Institute for cooperation and support. His experimental expertise helped in giving fundamental inputs for my research.

I owe a lot to the countless useful technical discussions and support of my friends in the CAFEE (Center of Alternative Fuels, Engines, and Emissions), CFD\&AMP (Computational Fluid Dynamics and Applied Multi-Physics Center) and ACCORD (Analytical and Computational Combustion Research Directions). I would like to take this opportunity to thank all my group mates especially Sinan Demir and Sri Hari Ram Challagalla for substantially assisting with my studies. Finally, I wish to conserve my last few lines for my family members, who have provided me with love and support.

I dedicate this work to the almighty who has always shown me the righteous path. 


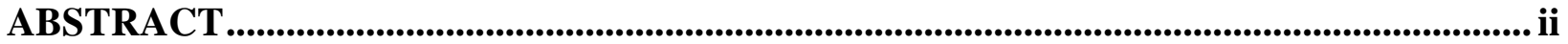

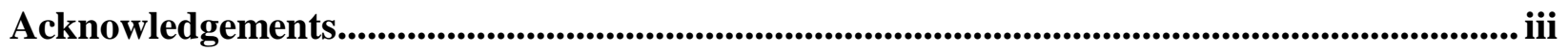

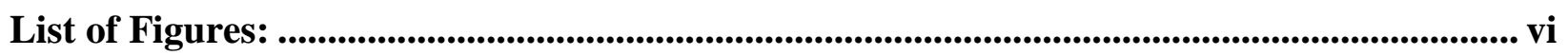

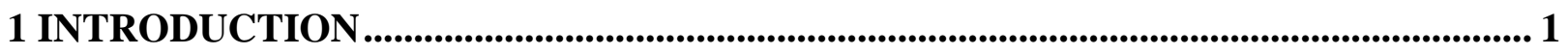

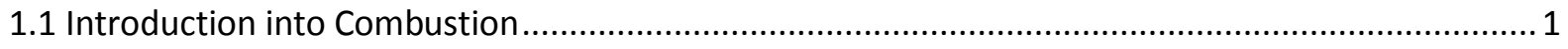

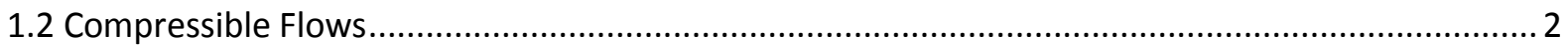

1.3 Regimes and Parameters of Premixed Combustion. Planar Flames ............................................... 3

2 FLAME ACCELERATION MECHANISMS .....................................................5

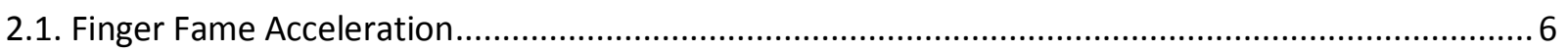

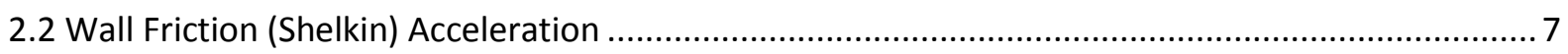

2.3 The Bychkov Mechanism (Obstacles) .................................................................................... 9

3 LITERATURE REVIEW ........................................................................................... 10

4 MOTIVATION AND OBJECTIVES ......................................................................... 12

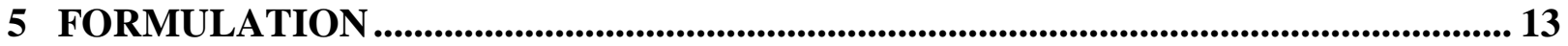

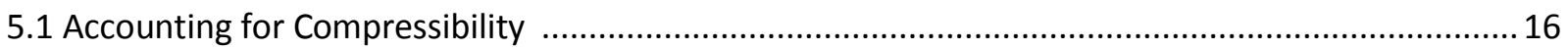

6 THE RUNGE-KUTTA METHOD OF NUMERICAL INTEGRATION..................... 18

7 RESULTS and DISCUSSION (Gaseous Combustion) ................................................. 19

8 EXTENSION TO DUSTY-GASEOUS COMBUSTION .................................................... 22

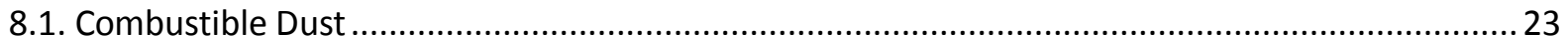

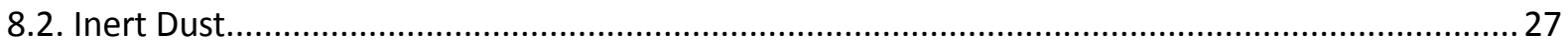

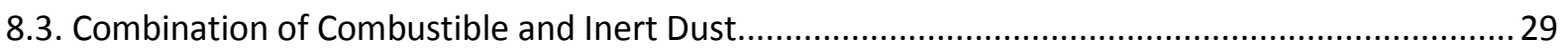

9 RESULTS and DISCUSSION (Dusty-Gaseous Environment) .................................... 30

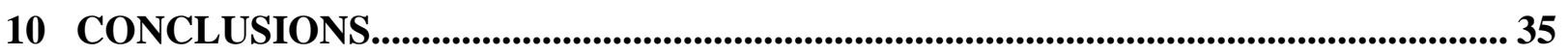

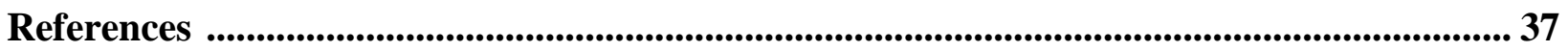




\section{NOMENCLATURE}

Symbols

c

$C_{p}$

C

C

$C_{s}$

$\boldsymbol{H}$

$\boldsymbol{K}_{u}$

Le

$\boldsymbol{L}_{f}$

$\mathrm{r}_{\mathrm{s}}$

n

$\operatorname{Pr}$

$Q$

$x$

$h$

$\boldsymbol{R e}$

$\boldsymbol{R}_{\boldsymbol{f}}$
Speed of Sound $(\mathrm{m} / \mathrm{s})$

Specific Heat at constant Pressure of the air fuel mixture $(\mathrm{kJ} / \mathrm{kgK})$

Total heat capacity $(\mathrm{kJ} / \mathrm{kg})$

Heat capacity of fresh air fuel mixture at a constant Volume $(\mathrm{kJ} / \mathrm{kgK})$

Heat capacity of dust particles $(\mathrm{kJ} / \mathrm{kgK})$

Distance of the point of ignition from a tunnel wall (m)

Thermal conductivity $\left(\mathrm{K} \cdot \mathrm{m} \cdot \mathrm{W}^{-1}\right)$

Lewis number

Flame thickness (m)

Particle Radius

Number of particles per unit volume $\left(\mathrm{m}^{-3}\right)$

Prandtl number

Heat released during combustion $(\mathrm{kJ})$

Distance along vertical direction (m)

Characteristic length scale (m)

Flame propagation Reynolds number

Radius of the flame skirt (m) 


\begin{tabular}{|c|c|}
\hline$T$ & Temperature (K) \\
\hline$T_{b}$ & Adiabatic flame temperature $(\mathrm{K})$ \\
\hline$T_{s}$ & Surface temperature of dust particles \\
\hline$T_{v}$ & Temperature at which devolatilization process is initiated \\
\hline$t_{r}$ & The time which the coal particles stay in the flame (sec) \\
\hline$t_{s p h}$ & Time Taken for evolution from spherical flame to Fig.ure flame (sec) \\
\hline$t$ & Time $(\mathrm{sec})$ \\
\hline$t_{\text {wall }}$ & Time taken for the flame skirt to contact the wall (sec) \\
\hline$S_{L}$ & Unstretched laminar flame speed $(\mathrm{m} / \mathrm{s})$ \\
\hline$U_{D L}$ & $\begin{array}{l}\text { Instantaneous global flame speed with respect to the fuel mixture (taking into } \\
\text { account the DL instability) }(\mathrm{m} / \mathrm{s})\end{array}$ \\
\hline$w_{v}^{\prime}$ & Devolatalization rate $\left(\mathrm{kg} / \mathrm{m}^{3} \mathrm{~s}\right)$ \\
\hline$w_{v}$ & Total mass of volatilities released per unit volume \\
\hline$z$ & Distance along axial direction $(\mathrm{m})$ \\
\hline$Z e$ & Zeldovich number \\
\hline$M a$ & Mach Number \\
\hline
\end{tabular}

\section{Greek Symbols}

$\boldsymbol{\Theta}$

Thermal expansion coefficient

$\boldsymbol{V}$ kinematic viscosity $\left(\mathrm{m}^{2} / \mathrm{s}\right)$

$\phi \quad$ Fuel-air equivalence ratio 


\begin{tabular}{ll}
$\vartheta$ & Instantaneous flame expansion factor \\
$\rho$ & Density $\left(\mathrm{g} / \mathrm{cm}^{3}\right)$ \\
$\lambda_{D L}$ & Darrieus-Landau cutoff wavelength \\
$\boldsymbol{b}$ & \\
$\boldsymbol{f}$ & Burnt matter \\
$\boldsymbol{s}$ & Flame conditions \\
$\boldsymbol{x}$ & Dust particles \\
$\boldsymbol{z}$ & Vertical coordinate \\
$\boldsymbol{1}$ & Axial coordinate \\
$\boldsymbol{2}$ & Fresh air fuel mixture \\
$\boldsymbol{0}$ & Burnt matter \\
\hline
\end{tabular}

Super Script

$*$ $* *$

****
Properties changed due to Coal Particles

Properties changed due to inert sand particles

Properties changed due to combination of both inert and coal particles 
List of Tables:

Table 4.1: Methane-air flame parameters $\quad$.............................................................................. 14

Table 8.2: Some physical parameters used in the study ............................................................ 27 
List of Figures:

Fig. 1.1: Essential condition for combustion [1] ................................................................. 1

Fig. 2.7: Steps involved in Schelkin Mechanism [8] ....................................................................... 8

Fig. 2.8: Description of Byckhov mechanism [15,16] .......................................................9

Fig. 3.1: Consecutive stages of the mining fire scenario: (a) ignition of an expanding flame; (b) formation of a cellular flame structure; (c) finger-flame acceleration; (d) flame propagation driven by wall-friction; and (e) flame spreading through obstacles [22]......... 10

Fig. 5.1: The time limitations of the finger flame acceleration, $t_{s p h}$, Eq. (5.9), and $t_{w a l l}$, Eq. (5.16), versus the equivalence ratio $\phi$ for methane-air flames with $h=1 \mathrm{~m}, n=1.4$ 16

FIG. 7.1: Comparison of the incompressible (dashed) and compressible (solid) formulations: evolution of the flame tip position $Z_{\text {tip }}$ (a) and its velocity $U_{\text {tip }}$ (b) for methane-air flames of various equivalence ratios: $\quad \phi=0.6 ; 0.8 ; 1.0 ; 1.4$. 20

FIG. 7.2: Comparison of the incompressible (dashed) and compressible (solid) formulations: maximal coordinate $Z_{t i p}\left(t_{\text {wall }}\right)$ (a) and velocity $U_{\text {tip }}\left(t_{\text {wall }}\right)(\mathbf{b})$, attained by a methane-air flame tip during the finger flame acceleration, versus the equivalence ratio $\phi$.

Fig. 8.1: The modified flame temperature (for methane air with combustible particles) vs

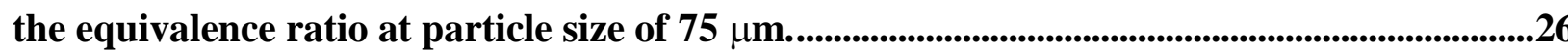

Fig. 8.2: The modified flame speed (for methane air with combustible particles) vs the

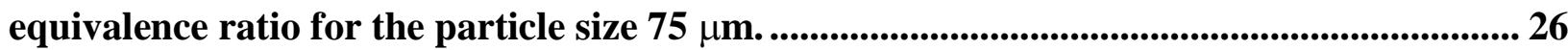

FIG. 8.3: The modified flame temperature (due to inert particles) vs the concentration of inert particles.

FIG. 8.4: The modified planar flame speed (due to inert particles) vs the concentration of inert particles.

Fig. 8.5: The modified flame temperature (due to combined of both particles) vs the concentration of combined particles

Fig. 8.6: The modified planar flame speed (due to combined of both particles) vs the concentration of combined particles.

FIG. 9.1: Comparison of the incompressible (dashed) and compressible (solid)

formulations: evolution of the flame tip position $Z_{t i p}$ (a) and its velocity $U_{t i p}$ (b) for

methane-air flames of equivalence ratio $\phi=0.7$ in the presence of combustible dust of concentration $c_{d}=120 \mathrm{~g} / \mathrm{cm}^{3}$ and mean particle radii $r_{s}=10 \mu \mathrm{m}, 75 \mu \mathrm{m}$

FIG. 9.2: Comparison of the incompressible (dashed) and compressible (solid) 
formulations: maximal coordinate $Z_{t i p}\left(t_{\text {wall }}\right)(\mathbf{a}, \mathbf{c})$ and velocity $U_{\text {tip }}\left(t_{\text {wall }}\right)(\mathbf{b , d})$, attained by 
the tip of methane-air-dust flames of various equivalence ratios $\phi=0.7,0.8,1.0$ during the finger acceleration, versus the concentration $c_{d}$ of combustible $(\mathbf{a}, \mathbf{b})$ and inert $(\mathbf{c}, \mathbf{d})$ dust of

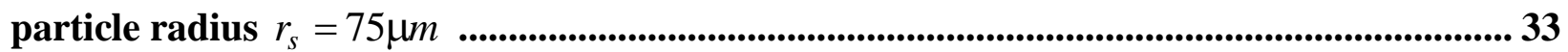

FIG. 9.3: Comparison of incompressible (dashed) and compressible (solid) formulations: evolution of the flame tip position $Z_{t i p}$ (a) and its velocity $U_{t i p}$ (b) for methane-air flames of equivalence ratio $\phi=0.7$ for no dust as well as in the presence of combustible and/or inert dust of concentration $c_{d}=120 \mathrm{~g} / \mathrm{cm}^{3}$ and mean particle radius $r_{s}=10 \mu \mathrm{m}$ 


\section{INTRODUCTION}

\subsection{Introduction into Combustion}

Combustion is a very old phenomenon. Indeed, a fire accompanied our primitive ancestors for millennia, providing them with heat and light, and thereby protecting from coldness, darkness, predators and stomach bacteria. Obviously, human fascination and addiction to combustion led to comprehensive investigations of this phenomenon. A combustion process occurs when a fuel gets oxidized, due to the presence of oxygen in the environment (say, atmosphere); this is a selfsustained and exothermic reaction. As illustrated in Fig. 1.1, the essential conditions for combustion are

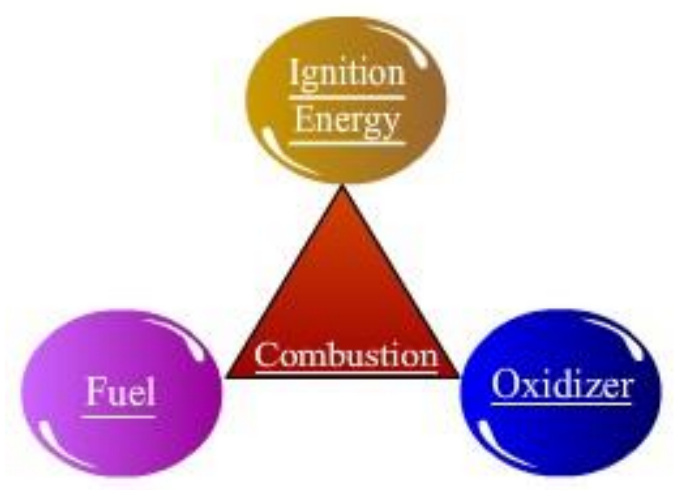

Fig. 1.1: Essential condition for combustion [1]

$\checkmark$ Presence of a fuel (typically, hydrogen or hydrocarbon);

$\checkmark$ Presence of an oxidizer (typically, air or pure oxygen; sometimes, fluorine);

Suitable fuel to oxidizer ratio (equivalence ratio); and

Ignition energy needed to be deposited to initiate the process.

In the one-step approximation, a hydrocarbon combustion reaction is given by

$$
\mathrm{C}_{\mathrm{n}} \mathrm{H}_{\mathrm{m}}+\left(n+\frac{m}{2}\right) \mathrm{O}_{2} \rightarrow n \mathrm{CO}_{2}+\frac{m}{2} \mathrm{H}_{2} \mathrm{O}
$$


with hydrocarbon compounds as typical fuels in the nature and industry; carbon dioxide $\left(\mathrm{CO}_{2}\right)$ and water vapor $\left(\mathrm{H}_{2} \mathrm{O}\right)$ being the burning products; and accompanied by inert nitrogen $\mathrm{N}_{2}$ from the air, when air is the oxidizer.

By the manner of processing, people distinguish premixed and non-premixed (or diffusion) regimes of combustion. Premixed burning occurs when both the fuel and the oxidizers are originally mixed such that, once ignited, a combustion wave front would propagate through the premixture in a self-supportive manner. The examples include gaseous appliances, gas turbines and spark-ignition (SI) engines, i.e. Otto (gasoline) engines. In contrast, diffusion burning occurs in combustors, where the fuel and the oxidizer were originally separated such that combustion is driven and accompanied by their mixing, i.e. diffusion. The examples are burning candles, forest fires or Diesel (compression-ignition; CI) engines.

This thesis is devoted to premixed combustion. The burning rate and the combustion efficiency depend on the equivalence ratio of the air/fuel mixture, which is the ratio of the actual fraction of the fuel in a mixture to that needed for the reaction. Mixtures having more fuel that needed for the reaction with the available amount of oxidizer have $\phi>1$ and are called (fuel)-rich ones. In

contrast, in the case of the oxidizer abundance over the fuel, $\phi<1$, the mixture is called to be a (fuel)-lean one. The mixtures with $\phi=1$ are called the stoichiometric mixtures. In most cases, near-stoichiometric air-fuel mixtures burns more efficiently and have higher burning rates as compared to the fuel-rich and fuel-lean mixtures.

\subsection{Compressible Flows}

A standard approach employed in numerous fluid mechanics studies is that of an incompressible 
flow, which means that the fluid density is assumed to be constant. However, a fluid element is 
typically compressed in the practical reality, due to its interactions with the neighboring parcels, pressure forces, chemical reactions and heat transfer. The latter is of relevance to combustion. The density variations are primarily due to the pressure variation along the fluid flow. Hence, in the practical reality, we have to deal with compressible flows, where we account for the density change across a fluid. An important dimensionless parameter characterizing a compressible flow is the Mach number, $M a \equiv u / c$, where $u$ is the characteristic flow velocity and $c$ is the sound

speed, being $c=\sqrt{\gamma R T}$ in the ideal gas model, where $\gamma=c_{p} / c_{v}$ is the adiabatic index, $R$ the specific gas constant and $T$ the temperature (in $\mathrm{K}$ ).

The Mach number is a threshold separating two types of flows - subsonic $(M a<1)$ and supersonic $(M a>1)$, which have different properties and need qualitatively different numerical methods of investigation.

\subsection{Regimes and Parameters of Premixed Combustion. Planar Flames}

In terms of Mach numbers, there are two conceptually different regimes of premixed combustion - deflagration (also known as "flame") and detonation. Deflagration is a slow, subsonic regime, where the reaction propagates due to thermal conduction (and diffusion). In contrast, detonation is a fast, supersonic regime of burning, which is driven by shock waves, which compress and thereby preheat the unburnt gas. Sometimes, a spontaneous deflagration-to-detonation transition (DDT) may occur. This is a huge disaster, preventing which is a key demand from the viewpoint of fire safety, and is one of the motivations of this study.

Figure 1.2 shows the internal structure of an "ideal" (planar, adiabatic) premixed deflagration 
(flame) front, with the associated temperature and density profiles presented in Fig. 1.3. Here, the flame front propagates from the right to the left. The reaction goes, majorly, in a thin active 
reaction zone, where the temperature is close to that of the burnt matter. The key parameters of such a flame are
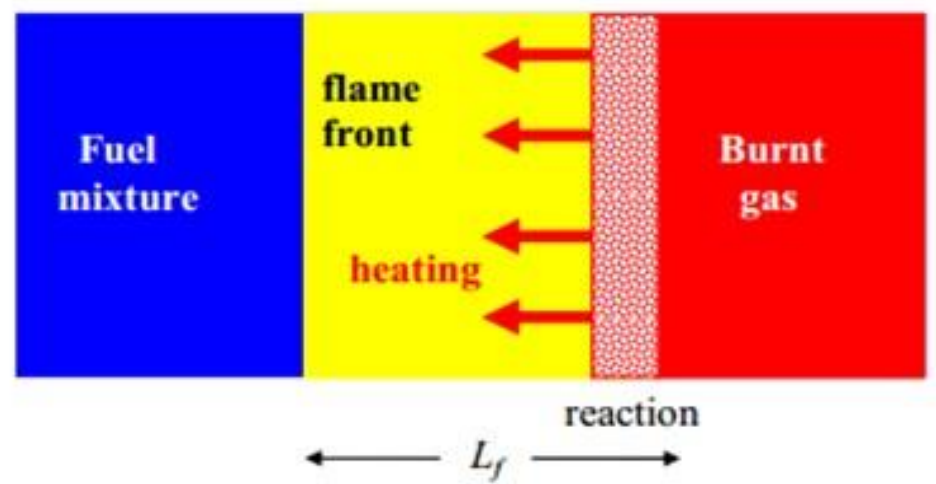

Fig. 1.2: A schematic view of a flame front travelling in an unburnt air fuel mixture [2]

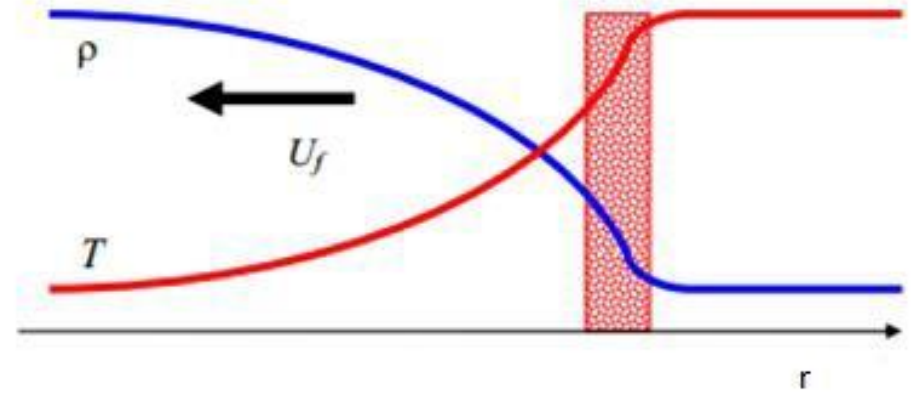

Fig. 1.3: Temperature and density variations across a flame front [2]

$\checkmark$ The thermal expansion coefficient (density drop at the flame front), $\Theta=\rho_{u} / \rho_{b} \approx T_{b} / T_{u}$.

Typically, $\Theta \approx 5-10$ such that with normal (room) temperature of the fuel being $\sim 300 \mathrm{~K}$ we find the adiabatic flame (burnt matter) temperature as large as $1500 \mathrm{~K} \sim 3000 \mathrm{~K}$ (the associated thermal expansion for the detonation is typically twice larger or about) [3].

$\checkmark$ The upstretched laminar (planar) flame speed $S_{L} \approx\left(10^{-1} \sim 10^{1}\right) \mathrm{m} / \mathrm{s}$.

$\checkmark$ The characteristic flame thickness, which us conventionally defined as $L_{f}=D_{t h} / S_{L}$, where $D_{t h}$ is the thermal diffusivity coefficient. It is nevertheless noted that the quantity $L_{f}$ is 
rather a characteristic transport parameter of length dimension, being typically, 
$L_{f} \approx\left(10^{-6} \sim 10^{-4}\right) m$, while the realistic width of the burning zone (determined by the temperature gradient) uses to appear up to an order of magnitude larger. In fact, $L_{f}$ rather correlates with the width of the active reaction zone than the real thermal flame thickness.

Anyway, the quantity $L_{f}$ is certainly much less than a characteristic size of a combustor, as illustrated in Fig. 1.4. For this reason, the conventional assumption of an infinitely thin flame (the so-called Landau limit) is widely employed in the combustion theory.

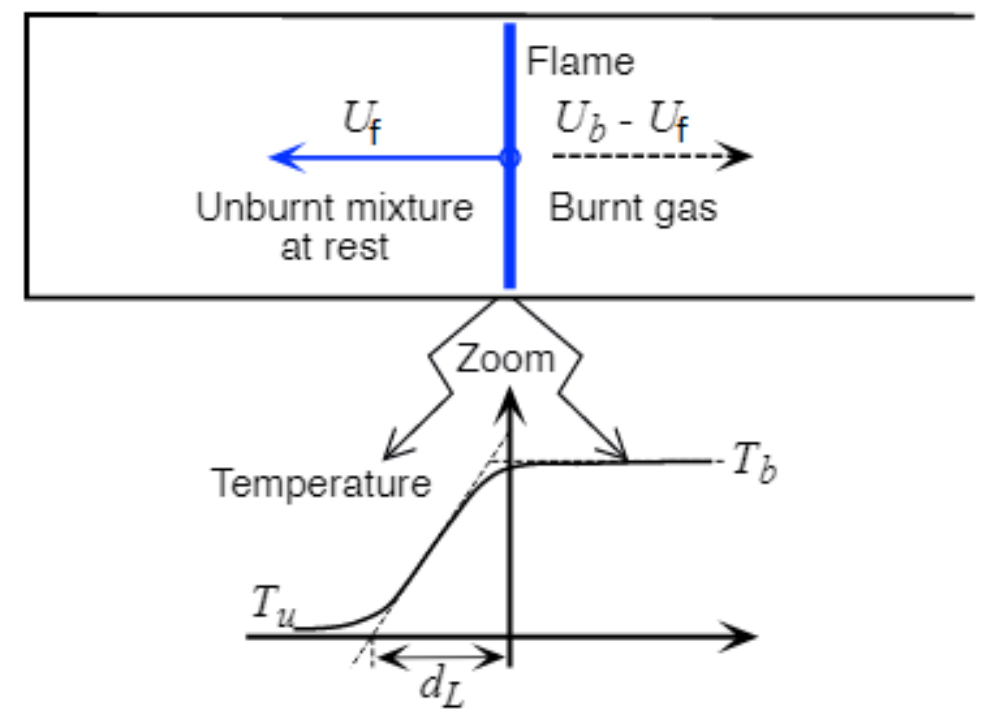

Fig. 1.4: Movement of a flame front with respect to the unburnt air fuel mixture [4]

\section{FLAME ACCELERATION MECHANISMS}

While a planar flame front of Figs. 1.2 - 1.4 would be simplest to investigate, it occurs ultimately seldom in the practical reality. Indeed, laboratory and industrial flames are usually corrugated. A curved flame front has a larger surface area relative to a planar one, involving the same mixture and under the same conditions; therefore, it consumes more fuel per unit time and release more 
heat, thereby propagating faster than the planar flame. Thus the flame accelerates. 
Various mechanisms can be responsible for such corrugation-driven acceleration. This includes, in particular, turbulence, acoustics, combustion instabilities as well as numerous peculiarities of flame propagation in pipes/tunnels. The latter is the core of this thesis; hence let us focus here on the acceleration mechanisms of flames in tubes, which are due to

$\checkmark$ Finger-like flame shape [5-7];

$\checkmark$ Wall friction (Schelkin mechanism) [8-14];

$\checkmark \quad$ In-built Obstacles [15,16].

All of them are introduced in brief below as follows.

\subsection{Finger Fame Acceleration}

Exponential acceleration is observed in premixed combustion during the early stages of the burning process due to a finger-shape acquired by a flame front [5-7]. Here, one of the tube ends is closed and the other end is open. Here, ignition occurs at the closed end.

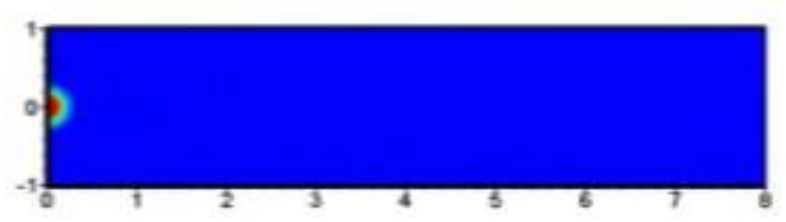

Fig. 2.1: Due to symmetry the flame is initially the flame is globally hemispherical [6].

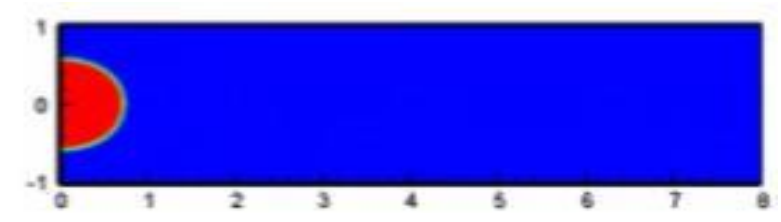

Fig. 2.2: Hemispherical Flame at the preliminary stage of combustion [6]

First, the movement of the flame front is constrained by the presence of tube walls, however the flame tip motion is unconstrained, and the flame expands freely. This results in flame getting 
corrugated and its shape transforms from globally hemispherical to finger shape. This results in an increase in flame surface area and burning rate ultimately leading to flame acceleration.

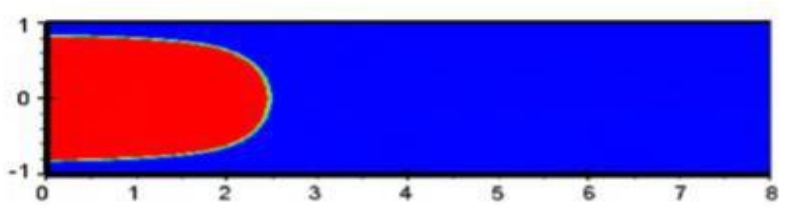

Fig. 2.3: Transition of a hemispherical flame to a finger flame [6]

However, this acceleration ceases as soon the flame skirt touches the tube walls. The flame begins to decelerate as and the flame shape transforms from finger shape to tulip shape.

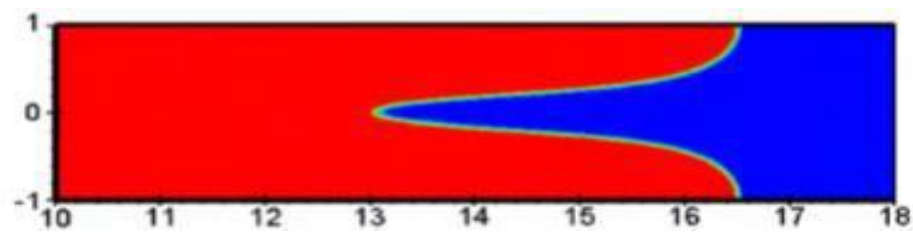

Fig. 2.4: Tulip Flame [6]

The tulip shape is very unstable and hence it collapses to become a planar flame. Since planar flames are very unstable, the flame again becomes corrugated due to the Darrieus-Landau (DL) instability.

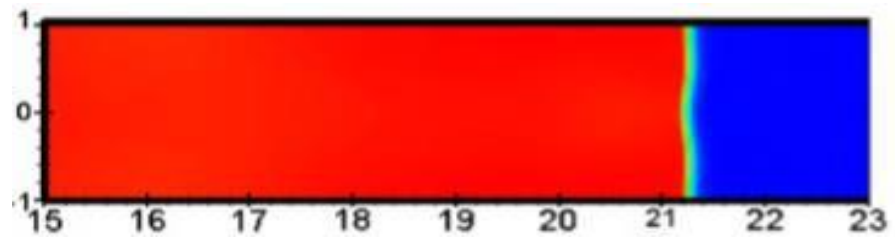

Fig. 2.5: DL flame [6]

\subsection{Wall Friction (Shelkin) Acceleration}

Spontaneous flame acceleration in a tube was explained by Shelkin [8]. Initially the flame is planar. Due to thermal expansion during the combustion process, the burnt matter pushes the unburnt air-fuel mixture. This flow of unburnt air-fuel mixture is called generated flow. The fluid in the vicinity of the walls is almost immobile due to nonslip boundary conditions; however, near 
the tube axis it attains the maximum velocity. Hence, the profile of air fuel mixture changes. This results in a change in the flame shape and an increase in the burning rate.

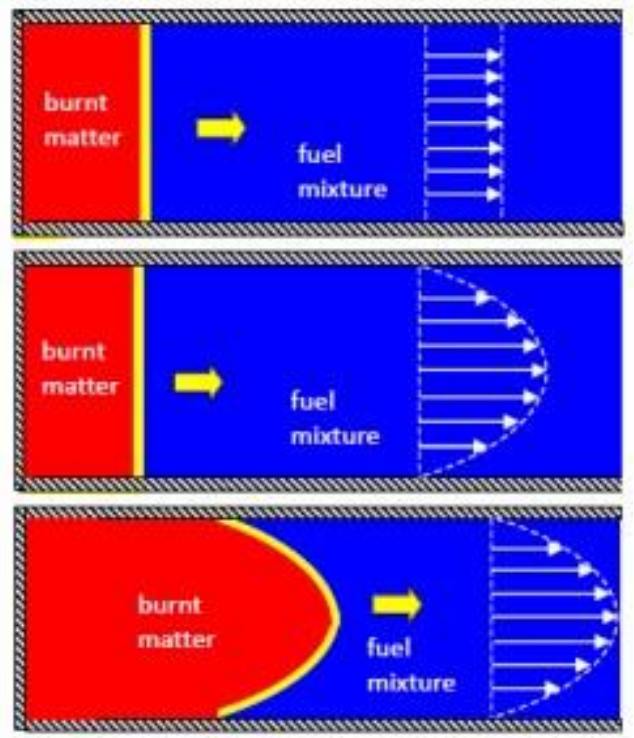

Fig. 2.6: Flame Corrugation due to the Schelkin Mechanism [8]

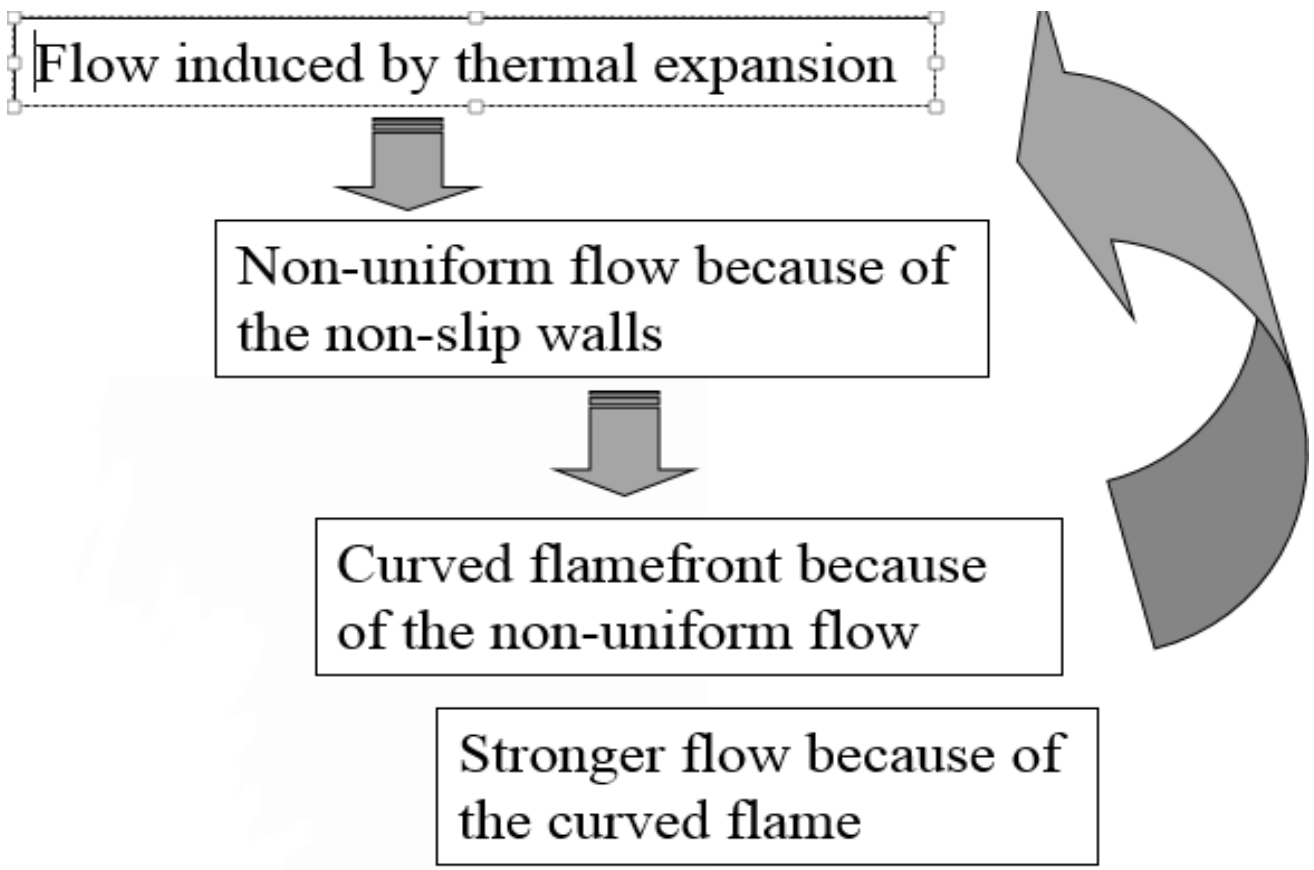

Fig. 2.7: Steps involved in Schelkin Mechanism [8] 


\subsection{The Bychkov Mechanism (Obstacles)}

The Bychkov mechanism of flame acceleration $[15,16]$ deals with combustion in obstructed pipes as illustrated in Fig. 2.8. Acceleration occurs due to the presence of obstacles. Similar to the finger flame acceleration, the movement of flame is constrained by the tube wall and unconstrained free expansion of burnt matter is observed in the unobstructed region of the channel. In the pockets between the obstacles, combustion is delayed. The thermal expansion in the obstructed region further intensifies the generated flow in the unobstructed region. It promotes a jet-flow, leading to flame acceleration $[15,16]$.

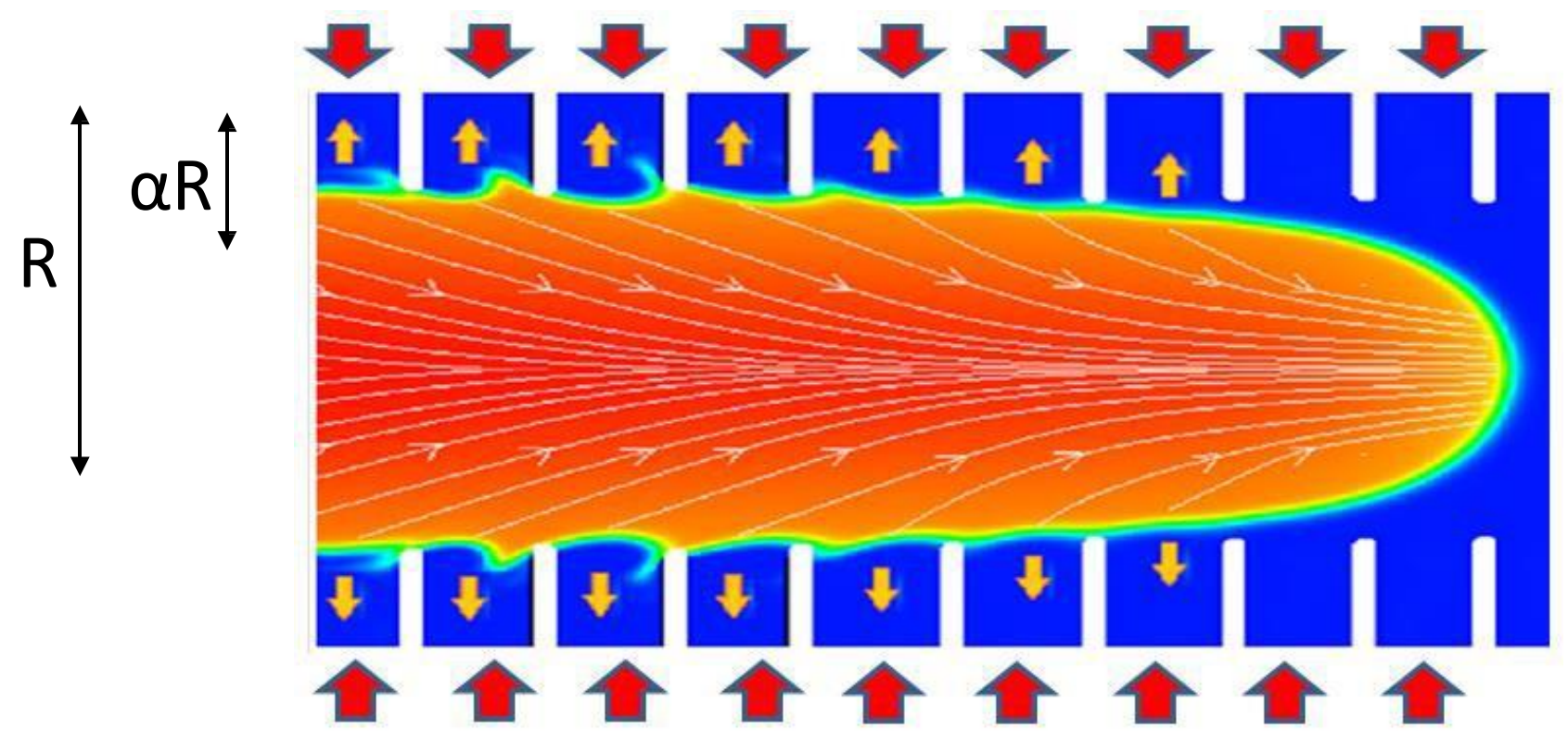

Fig. 2.8: Description of Byckhov mechanism [15,16] 


\section{LITERATURE REVIEW}

Accidental gas/dust explosions constitute a tremendous hazard for personnel and equipment in industries dealing with flammable gases and explosive materials such as the coal mining industry. The latter has one of the highest occupational fatality and injury rates, claiming hundreds of miners' lives annually [17]. Mining accidents are typically associated with spontaneous methane explosions in dusty mining passages, followed by comprehensive methane- air-dust fires. Preventive mining fire safety strategies include: prevention of the fire initiation (explosion); suppression/mitigation of the fire spreading if it was nevertheless sparked; and (if a fire cannot be terminated) prevention of a deflagration-to-detonation transition (DDT), because a shock-wise nature of a detonation constitutes a huge disaster in mines even without combustion. These strategies require fundamental understanding of all intermediate stages of the methane-air- dust fire evolution. Unfortunately, in spite of recent experimental [18] computational $[19,20]$ and theoretical [21] studies shedding some light on dusty-gaseous combustion, there is still much to be done to reduce the level of fire/explosion risk in mines and managing combustible dusts [17].

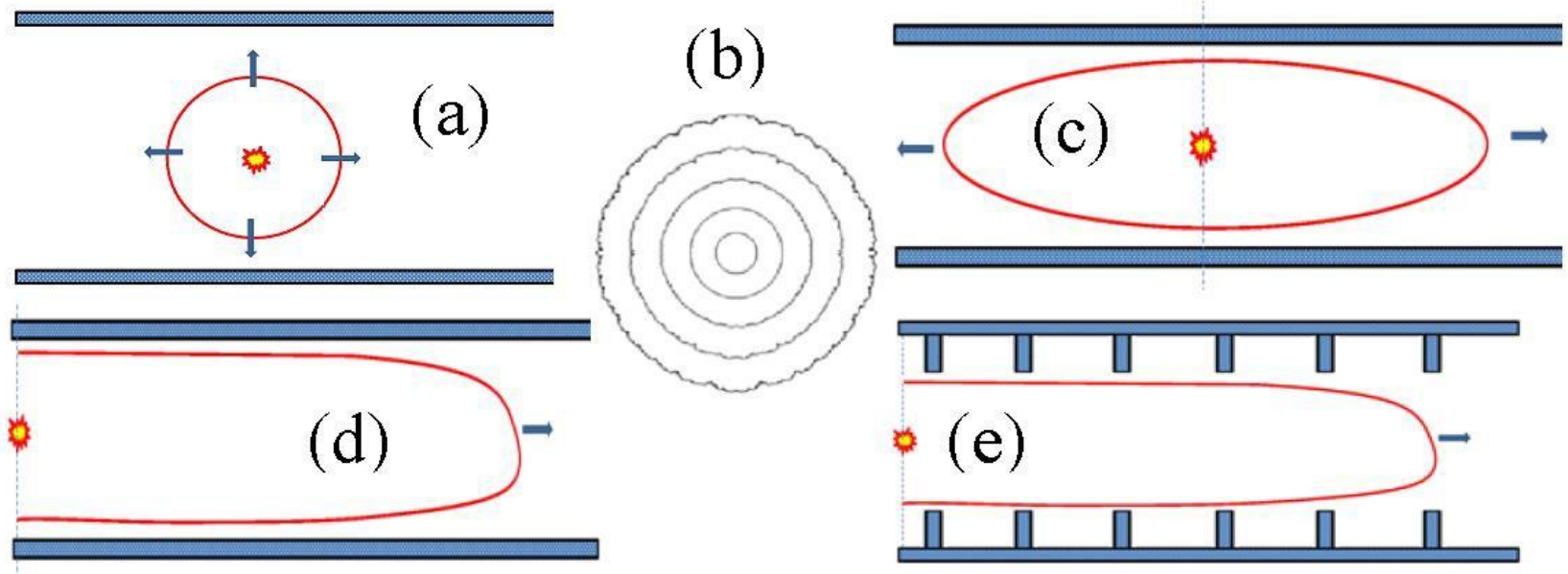

Fig. 3.1: Consecutive stages of the mining fire scenario: (a) ignition of an expanding flame; (b) formation of a cellular flame structure; (c) finger-flame acceleration; (d) flame propagation driven by wall-friction; and (e) flame spreading through obstacles [22]. 
To provide guidance for preventing and controlling fire disasters in mines, Akkerman et al [22] have developed a predictive quantitative scenario of a methane-air-dust mining fire, as illustrated in Fig. 3.1. As any premixed flame, fire spreading is characterized by the unstretched laminar flame velocity $S_{L}$; if a flame front was planar, it would propagate with this speed with respect to the fuel mixture. However, the flame front is not planar, but strongly corrugated such that it consumes more fuel per unit time and propagates faster. Further, the experiments by Rockwell and Rangwala [23] yielded that flame corrugation increases with the presence of dust particles.

The scenario includes several conceptually distinctive stages [22]. First, an initially smooth flame front, Fig. 3.1a, experiences a cellular Darrieus-Landau (DL) instability that may amplify the flame velocity by an order of magnitude in a space of a human height size, Fig. 3.1b [24]. Second, when a flame front starts approaching the tunnel wall, it slows down in the radial direction but accelerates in the axial one, thereby acquiring a "finger-like" shape, Fig. 3.1c [5-7]. Overall, the finger-flame surface area grows very fast, which promotes the flame velocity by one more order of magnitude by the time when the flame front contacts a wall [6]. This finger-shape acceleration is Reynolds-independent, being equally strong in micro-pipes and mining passages. Third, finger-like acceleration stops after a flame front contacts a wall. Then the flame may further accelerate due to wall friction, Fig. 3.1d [8-14], and/or in-built obstacles, Fig. 3.1e $[15,16]$. However, while both of these acceleration mechanisms are of primary importance for some configurations, their role is minor in a mining passage [22]. Consequently, the finger acceleration is the dominant mechanism in a mining deflagration, and thereby this was a focus of Ref. [22]. Specifically, the "DL" and "finger" acceleration stages in gaseous and dusty environments were combined into a unified analytical formulation. The input parameters for this 
formulation include the geometry of a mining passage, the methane/air equivalence ratio as well as the size, concentration and other properties of the inert/combustible dust.

\section{MOTIVATION AND OBJECTIVES}

It is noted that the "pilot" formulation [22] did not account for certain factors from the mining practical reality such as turbulence and spatial/temporal variations of the premixture, but what is more important - it was derived within the approach of incompressible flows. While this is acceptable for initial (isobaric) stage of combustion, gas compression certainly becomes substantial by the end of the "finger" stage, Fig. 3c, when a flame front may attain near-sonic velocities. Gas compression moderates flame acceleration in various configurations $[7,14,16]$, hence the same effect is anticipated in a mining geometry, and verifying this statement constitutes the objectives and focus of the present work. To be specific, we shall quantify the role of gas compression in finger flame acceleration in a mining passage, thereby validating the incompressible formulation [22]. For simplicity, a two-dimensional (2D) configuration will be used, which is acceptable to relate the incompressible and compressible analyses; a realistic three-dimensional (3D) configuration will be considered elsewhere. Specifically, we shall actually develop a 2D counterpart of the theory [22] and then extend it to account and identify the relative contribution of gas compression. Starting with gaseous combustion, the formulation will also be extended to dusty-gaseous flows. The effects of equivalence ratio and dust size/concentration on the flame dynamics will be systematically studied investigated. 


\section{FORMULATION}

We consider an accidental ignition of a methane-air premixture occurring at a point at a distance $h$ from a side wall of a 2D tunnel, as illustrated in Fig. 3.1. At the early stage of burning, the flame front expands outwardly from the ignition point, as a circle, with a constant velocity $d R_{f} / d t=\Theta S_{L}$ with respect to the ignition point, Fig. 3.1a, where $R_{f}$ is the flame radius, $\Theta=\rho_{u} / \rho_{b}$ the thermal expansion factor, which is coupled to the equivalence ratio $\phi$, and $S_{L}$

the unstretched laminar flame speed; see Table 1 [25]. As the flame "circle" grows, the DL instability will eventually develop, continuously generating new cells over the flame surface, thereby increasing the volumetric flame surface density [24]. As a result, an expanding flame self-accelerates in a self-similar manner, Fig. 3.1b. According to numerous experimental and computational studies, a reasonable fitting law for such acceleration is [24]

$$
R_{f}=R_{0}+C t \underset{n}{\approx}{ }_{n}, C=\left(\lambda_{D L} / 2 \pi\right) \quad\left(\Theta S_{L} / n\right),
$$

where $n \approx 1.3-1.4$, and $\lambda_{D L}$ is the DL cutoff wavelength which depends on $\Theta$ and is

proportional to the flame thickness $L_{f}$. Here we employ the formula [26]

$$
\lambda_{D L}=2 \pi L_{f}\left\{+(\Theta+1) \Theta \ln \Theta(\Theta-1)^{2}\right\}
$$

such that $\lambda_{D L} \approx 25 L_{f}$, though any other formulation for $\lambda_{D L}$ can readily be incorporated into the analysis. With the power-law flame acceleration, Eq. (5.1), the instantaneous global (radial) flame speed with respect to the fuel mixture is not $S_{L}=$ const, but a time-dependent quantity 


$$
U_{D L}=\Theta^{-1} d R \quad / d t=(n C / \Theta) t^{n-1} .
$$

\begin{tabular}{|llllllllll|}
\hline$\phi$ & 0.6 & 0.7 & 0.8 & 0.9 & 1 & 1.1 & 1.2 & 1.3 & 1.4 \\
$\Theta$ & 5.54 & 6.11 & 6.65 & 7.12 & 7.48 & 7.55 & 7.43 & 7.28 & 7.09 \\
\hline
\end{tabular}




\begin{tabular}{|llllllllll|}
\hline$S_{L}(\mathrm{~m} / \mathrm{s})$ & 0.089 & 0.169 & 0.254 & 0.325 & 0.371 & 0.383 & 0.345 & 0.250 & 0.137 \\
\hline
\end{tabular}

Table 5.1: Methane-air flame parameters [25]

Equations (5.1) - (5.3) describe the accelerative flame expansion in an opening. However, when a flame starts approaching (even not contacting yet!) a (tunnel) wall, the difference between the radial and axial flows modifies the flame shape, forming two outwardly propagating "fingerlike" fronts, Fig. 3.1c. In fact, the expansion of the burning matter leads to a strong flow in the axial direction, which drifts the tip of a finger-shaped flame. Because of the elongated shape, the surface area of the flame front is much larger than the passage cross-section. As a result, the flame accelerates. However, this acceleration stops as soon as the flame "skirt" contacts the passage wall.

Similar to Ref. [22], we next combine the above expanding flame analyses with a finger-flame formulation [6] by employing a time-dependent quantity $U_{D L}(t)$, Eq. (5.3), instead of $S_{L}$. Then,

with the approach of a potential flow, the $2 \mathrm{D}$ incompressible continuity equation, $\nabla \mathbf{u}=0$, has the solutions

$$
u_{z, 1}=A_{1}(t) z, \quad u_{x, 1}=A_{1}(t)(h-x), \quad u_{z, 2}=A_{2}(t) z, \quad u_{x, 2}=-A_{2}(t) x
$$

For the $z$ - and $x$-velocities ahead (index 1) and behind (index 2) the flame front. The matching conditions at the front, $x=R_{f}$, are

$$
d R_{f} / d t-u_{x, 1}=U_{D L}(t), \quad u_{x, 1}-u_{x, 2}=(\Theta-1) U_{D L}(t), \quad u_{z, 1}=u_{z, 2}
$$

Equations (5.3) - (5.5) provide the evolution equation for the flame skirt

$$
d R_{f} / d t
$$




$$
\begin{aligned}
& =\{(\Theta-1)(1 / h)+1\}_{D L} \quad=\{(\Theta-1)(/ h)+1\}(n C / \\
& -R_{f} \\
& \left.1-R_{f} \quad \Theta\right) t^{n-1}
\end{aligned}
$$


with

$$
A_{1}=A_{2}=(\Theta-1) U_{D L}(t) / h
$$

the initial condition $\left.R_{f}\right|_{t=0}=0$, and the solution

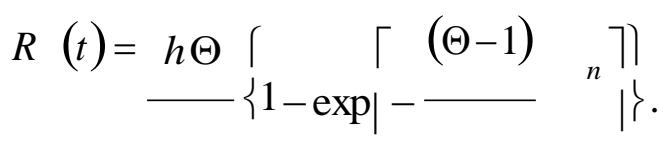

$$
\begin{aligned}
& \text { f } \quad \Theta-1 \mid \\
& \left.\left\lfloor\quad \Theta h^{C t}\right\rfloor\right\rfloor
\end{aligned}
$$

A characteristic time instant devoted to the transition from a globally-spherical to a finger-like flame shape, $t_{s p h}$, as well as the corresponding flame velocity $U_{D L}\left(t_{s p h}\right)$ and "radius" $R_{f}\left(t_{s p h}\right)$

can be evaluated as

$$
\begin{aligned}
& t_{s p h} \approx[h \Theta /(\Theta-1) C]^{1 / n}, \\
& U_{D L}\left(t_{s p h}\right)=(n C / \Theta) t^{n-1}=n(C / \Theta)^{1 / n}[h 2(\Theta-1)]^{(n-1) / n}, \\
& R_{f}\left(t_{s p h}\right)=\left(1-e^{-1}\right) h \Theta(\Theta-1)=0.632 h \Theta(\Theta-1) .
\end{aligned}
$$

The evolution equation for the flame tip reads

$$
d Z_{t i p} / d t-u_{z, 2}=\Theta U_{D L}(t)
$$

or

$$
d Z_{t i p} / d t=(\Theta-1)\left(Z_{t i p} / h\right) U_{D L}(t)+\Theta U_{D L}(t)
$$

with the solution

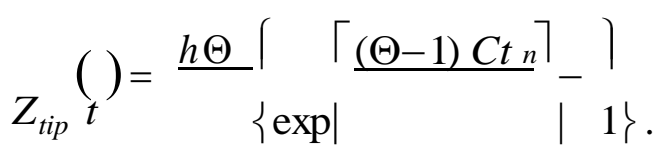

$$
\begin{aligned}
& \Theta-1\left\lfloor\left\lfloor\begin{array}{ll}
\qquad & h\rfloor\rfloor
\end{array}\right.\right.
\end{aligned}
$$


The flame tip velocity in the laboratory reference frame is therefore

$$
U_{t i p}(t)=\frac{d Z_{\text {tip }}}{d t}=n C t^{-1} \exp \left|\frac{\left\lceil(\Theta-1) C t^{n}\right\rceil}{\Theta \quad h\rfloor}\right| .
$$

The flame skirt contacts the tunnel wall when $R_{f}=h$, i.e. at the time instant $t_{\text {wall }}$ given by

$$
t_{\text {wall }}=[h \Theta \ln \Theta(\Theta-1) C]^{1 / n}
$$


such that $t_{\text {wall }} / t_{s p h}={ }^{n} \ln \Theta$. The quantities $t_{s p h}$, Eq. (5.9), and $t_{\text {wall }}$, Eq. (5.16), determines the limits of the finger flame acceleration. They are presented in Fig. 5.1 versus the methane-air equivalence ratio $\phi$ for $n=1.4$ and $h=1 \mathrm{~m}$, with the relation between $\Theta$ and $\phi$ from Table

5.1. Obviously, near-stoichiometric combustion corresponds to largest $\Theta$ and thereby fastest flame propagation and shortest $t_{s p h}$ and $t_{\text {wall }}$, while very lean or rich combustion spreads much

slower, making these timings an order of magnitude larger. The finger-flame acceleration terminates at $t_{\text {wall }}$, with the flame tip position, Eq. (12), at this instant being $Z_{\text {tip }}\left(t_{\text {wall }}\right)=h \Theta$,

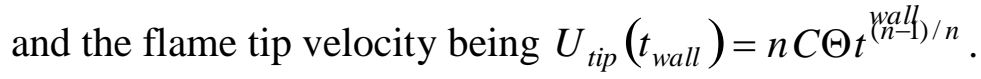

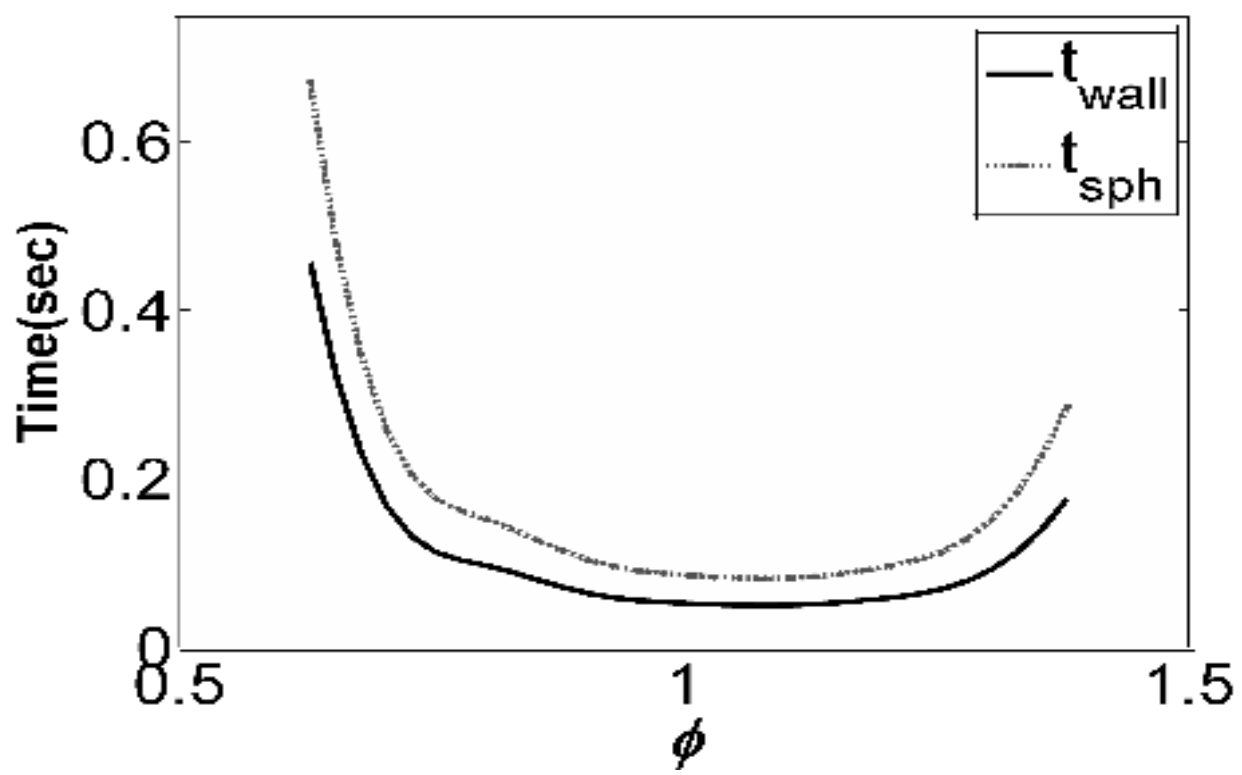

Fig. 5.1: The time limitations of the finger flame acceleration, $t_{s p h}, E q .(5.9)$, and $t_{\text {wall }}$, Eq. (5.16), versus the equivalence ratio $\phi$ for methane-air flames with $h=1 \mathrm{~m}, n=1.4$

\subsection{Accounting for Compressibility}


The analysis above is a $2 \mathrm{D}$ counterpart of the formulation [22]. We next extend it to account for small but finite Mach number based on the methodology of Ref. [7]. Namely, the approach is based on the first-order extension in small, but finite Mach number associated with the flame 
propagation. However, while such a Mach number was constant, $M a=S_{L} / c_{0}$, in Ref. [7], here this is a time-dependent quantity

$$
M a(t)=U_{D L}(t) / c_{0}=(n C / \Theta) t^{n-1} / c_{0}
$$

where $U_{D L}(t)$ is given by Eq. (5.3) and $c_{0}$ is the initial sound speed in the fresh mixture. While combustion is substantially subsonic, $M a<<1$, the flow in the unburnt gas can be treated as isentropic, with the instantaneous density, pressure and temperature given by

$$
\begin{aligned}
& \left.\frac{\rho_{u}(t)}{\rho_{0}}=\left(\begin{array}{cc}
1_{\perp} \gamma-1 & u_{z, 1}(t) \\
2 & c_{0}
\end{array}\right)\right)^{2 /(\gamma-1)} \approx 1+M a(t)(\Theta-1)\left(1+\frac{Z_{t i p}(t)}{h}\right), \\
& \frac{P_{u}(t)}{P_{0}}=\left(1, \frac{\gamma-1 u_{z, 1}(t)}{2 c^{0}}\right)^{i \gamma /(\gamma-1)} \approx 1+\gamma \operatorname{Ma}(t)(\Theta-1) \mid\left(1+\frac{L_{t i p}(t)}{h}\right),
\end{aligned}
$$

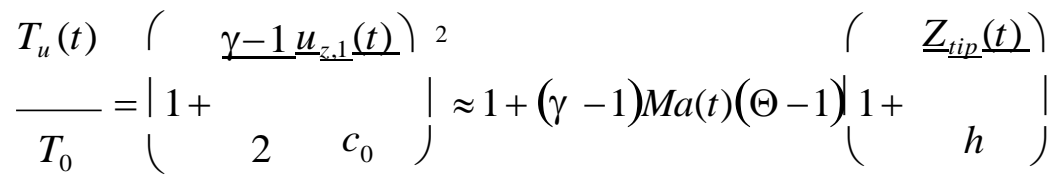

(see Ref. [3] for more details). Here $\gamma=c_{p} / c_{v} \approx 1.4$ is the adiabatic index and $\rho_{0}, P_{0}, T_{0}$ are initial values in the unburnt gas. Instead of initial thermal expansion $\Theta$, here we use an instantaneous (reduced) expansion factor

$$
\vartheta(t)=\Theta-(\gamma-1) M a(t)(\Theta-1)^{2}\left\{1+Z_{t i p}(t) / h\right\} .
$$

The $2 \mathrm{D}$ continuity equation for small but finite compressibility, $\nabla \mathbf{u}=-\left(\partial P_{u} / \partial t\right) / \gamma P_{u}$, has the solution in the burnt gas

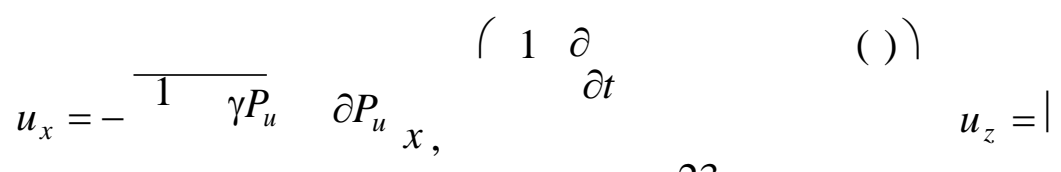




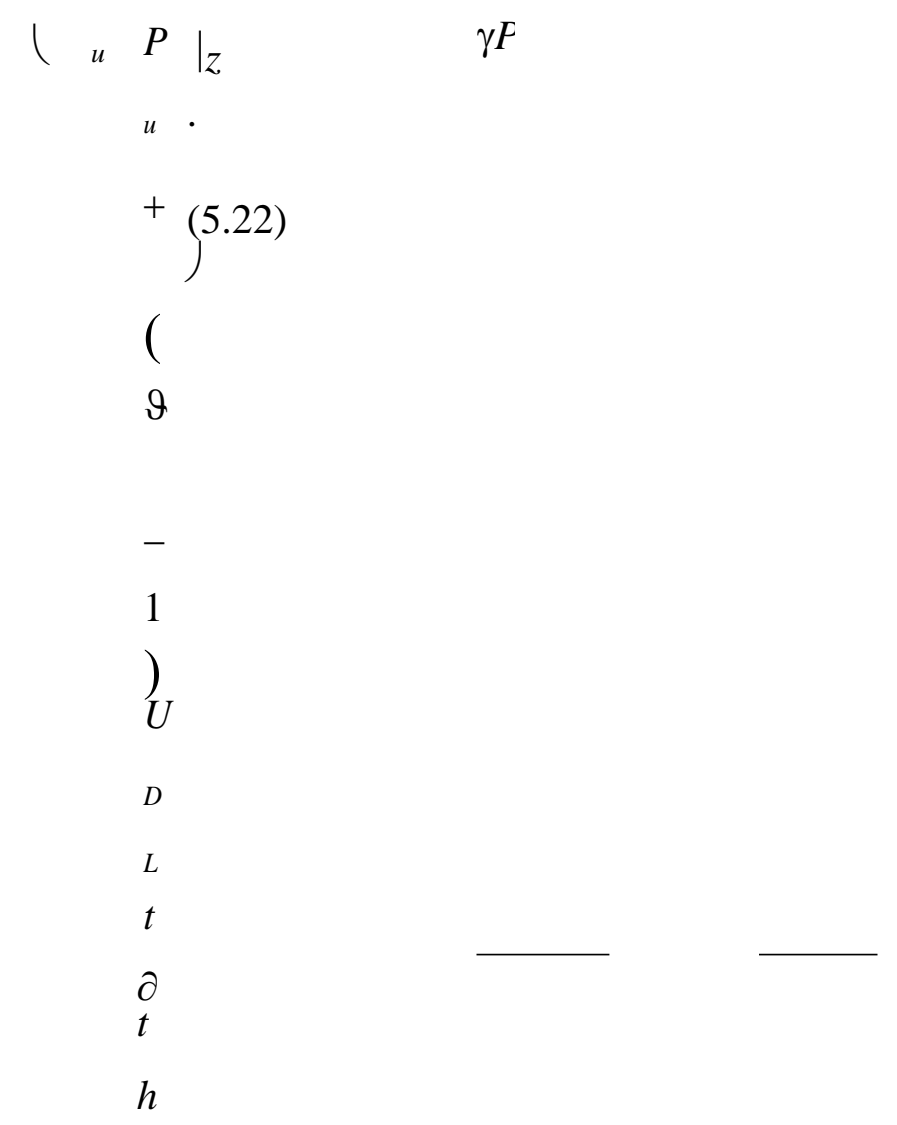

Substituting Eqs. (5.17) - (5.22) into a modified Eq. (5.12),

$$
\dot{Z}_{t i p}-u_{z, 2}(\vartheta(t))=\vartheta(t) U_{D L}(t)
$$


and further neglecting second and higher order terms in $M a$, we eventually arrive to the final evolution equation for the flame tip

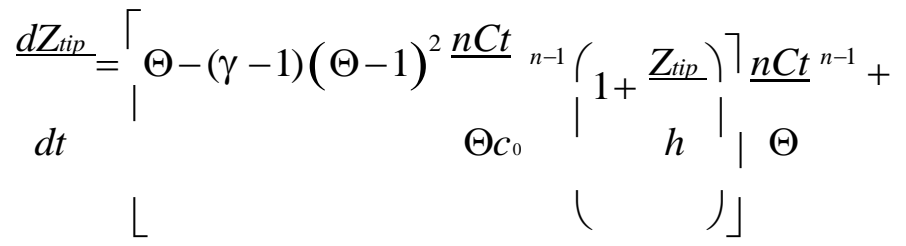

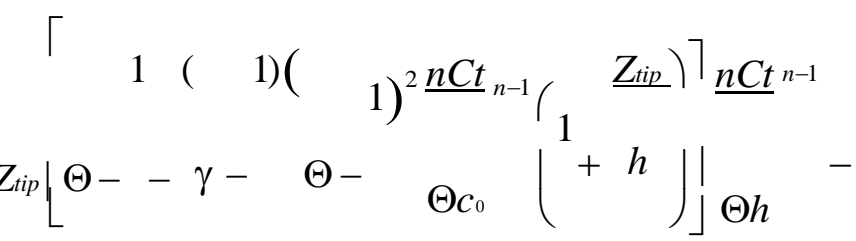

$$
\begin{aligned}
& \left(1+\underline{Z_{t i p}}\right) \underline{n(n-1) C t^{n-2}}-\left(1+\frac{\Theta-1}{\left.Z_{t i p}\right)}\right) \underline{n^{2} C^{2} t^{2 n-2}} . \\
& (h) \Theta c_{0}(\Theta h) \Theta h c_{0}
\end{aligned}
$$

\section{THE RUNGE-KUTTA METHOD OF NUMERICAL INTEGRATION}

Equation (5.24) cannot be solved analytically; hence, we integrate it numerically employing the Runge-Kutta computational technique to achieve high-order accuracy of numerical integration. Here the basics of the method are recalled. Assume he have a first-order differential equation

$$
\frac{d y}{d t}=f(\mathrm{t}, \mathrm{y})
$$

having an initial boundary condition

$$
\mathrm{y}\left(\mathrm{t}_{0}\right)=\mathrm{y}_{0}
$$

and the numerical scheme is defined with a grid size $\Delta t$. The solution for the next grid point is

$$
\begin{aligned}
& y_{t}+\Delta t=y_{t}+\frac{\Delta t}{6}\left(k_{1}+2 k_{2}+2 k_{3}+k_{4}\right), \\
& k_{1}=f\left(t, y_{t}\right), \\
& k_{2}=f\left(t+\frac{\Delta t}{2}, y_{t}+\frac{\Delta t}{2} k_{1}\right),
\end{aligned}
$$




$$
k_{3}=f\left(t+\frac{\Delta t}{2}, y_{t}+\frac{\Delta t}{2}^{\left.k_{2}\right),}\right.
$$




$$
k_{4}=f\left(t+\Delta t, y_{t}+\Delta t k_{3}\right),
$$

The total accumulated error is of the order of magnitude $O\left((\Delta t)^{4}\right)$. Hence the grid size $\Delta \mathrm{t}$ is taken as a very small value.

\section{RESULTS and DISCUSSION (Gaseous Combustion)}

Equation (5.24) describes the effect of gas compression on finger flame acceleration in a mining passage. It has been solved numerically and compared to the incompressible formulation (5.14), (5.15) for a variety of methane-air parameters. Since, the DL velocity $\left(U_{D L}\right)$ is a power law with time and consequently low Mach number $M a(t)$, during the early stages of combustion i.e. from the beginning till "finger" transition at the instant $t_{s p h}$ we ignore the effect of compressibility. Specifically, Fig. 7.1 presents the methane-air flame evolution for various $\phi=0.6 \sim 1.4$, between the instants $t_{s p h}$, Eq. (5.9) and $t_{\text {wall }}$, Eq. (5.16), i.e. during the entire finger flame scenario. Figure 7.1a shows the flame tip position, while its velocity is shown in Fig. 7.1b. In both figures the compressible, Eq. (5.24), and incompressible, Eqs. (5.14), (5.15), formulations are shown by the solid and dashed lines, respectively. It is seen that in agreement with our anticipation, gas compression moderates the acceleration process. Still, the effect is minor for lean and rich mixtures, whereas it is substantial for near-stoichiometric combustion (strongest acceleration).

The same result is also justified in Fig. 7.2, where the maximal flame tip position, $Z_{\text {tip }}\left(t_{\text {wall }}\right)$,

Fig. 7.2a, and velocity $U_{\text {tip }}\left(t_{\text {wall }}\right)$, Fig. 7.2b, are presented versus $\phi$. Figure 7.2a is probably the most interesting result of this work as it shows a qualitative difference between the 
incompressible and compressible approaches. Indeed, while the incompressible analysis anticipatively yields the maximal $Z_{\text {tip }}\left(t_{\text {wall }}\right)$ for near-stoichiometric combustion, $\phi=1.1$, with 
the reductions in $Z_{\text {tip }}\left(t_{\text {wall }}\right)$ for leaner and richer flames, Eq. (5.24) shows a monotonic increase in $Z_{\text {tip }}\left(t_{\text {wall }}\right)$ with $\phi$ within the entire range.

(a)
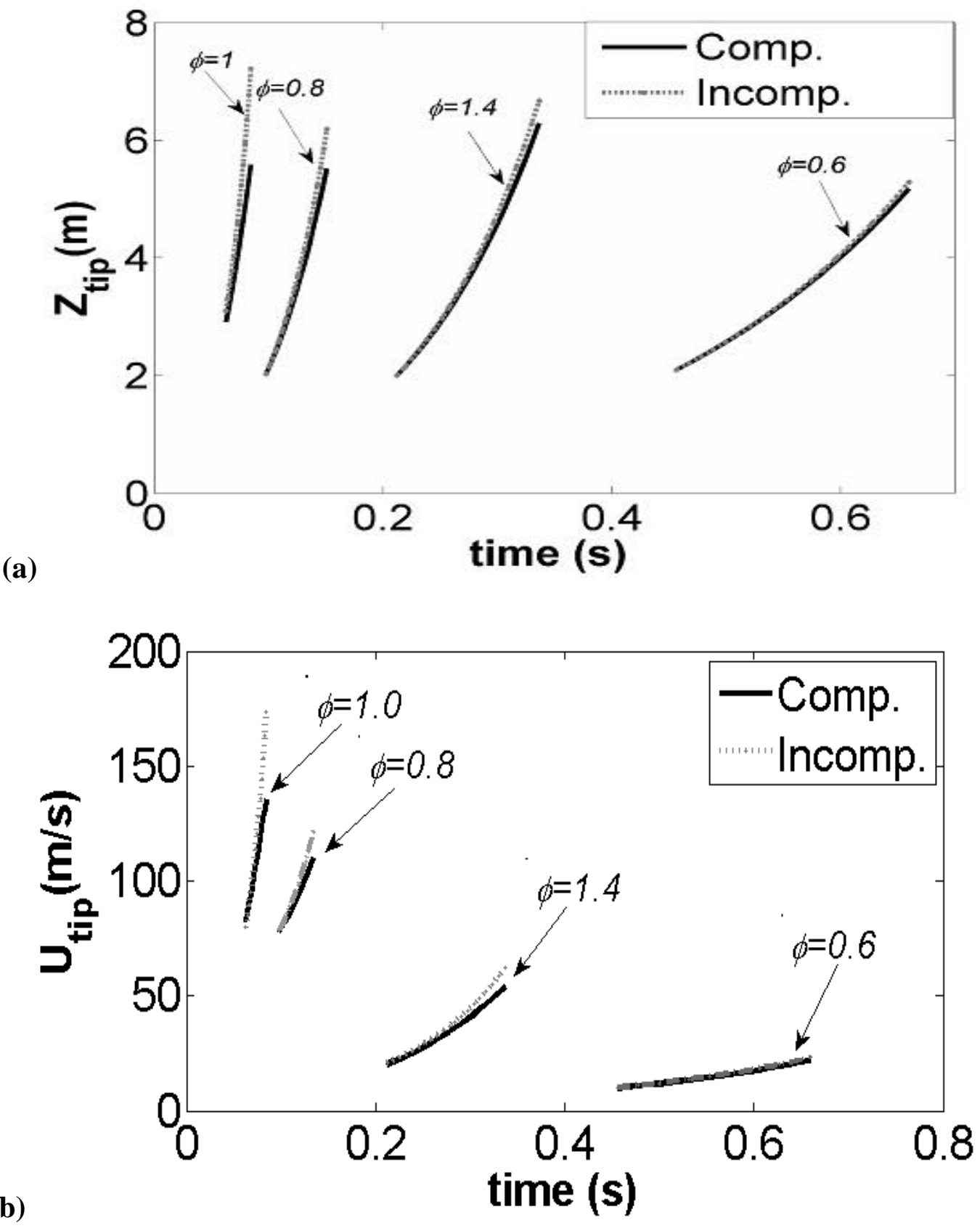

FIG. 7.1: Comparison of the incompressible (dashed) and compressible (solid) formulations: evolution of the flame tip position $Z_{\text {tip }}(a)$ and its velocity $U_{\text {tip }}$ (b) for methane-air flames of various equivalence ratios: $\phi=0.6 ; 0.8 ; 1.0 ; 1.4$. 
Specifically, it grows noticeably in the lean $(0.6 \leq \phi \leq 0.9)$ and rich $(1.1 \leq \phi \leq 1.3)$ branches, being near-constant for $0.9 \leq \phi \leq 1.1$. Opposite trends that the curves in Fig. 7.2a exhibit for $\phi>1.1$ justify the role of gas compression that may control the acceleration process for reach flames. However, this is not the case for Fig. 7.2b, where both approaches show qualitatively the same trends for the maximal flame tip velocity $U_{\text {tip }}\left(t_{\text {wall }}\right)$. Nevertheless, a noticeably quantitative difference is also seen in Fig. 7.2b: the reduction in $U_{\text {tip }}\left(t_{\text {wall }}\right)$ due to gas compression varies from 3-5 \% for lean/rich mixtures till the maximum of $22 \%$ for $\phi=1.1$. Such a reduction of the maximal velocity attained by a flame during the finger acceleration scenario certainly diminishes the risk of DDT as compared to the incompressible predictions [22]. Nevertheless, even Eq. (5.24) shows 1-2 orders of magnitude increase in the flame velocity as compared to the nominal value $S_{L}$.

As a result, we have validated the incompressible formulation [22] for various equivalence ratios as shown in Figs. 7.10 and 7.2. To be rigorous, Eq. (5.16) for $t_{\text {wall }}$ should also be extended to account for gas compression: moderation of acceleration makes a flame front contacting the tunnel wall later. However, $t_{\text {wall }}$ depends on gas compression very slightly [7], so this effect is neglected here. 


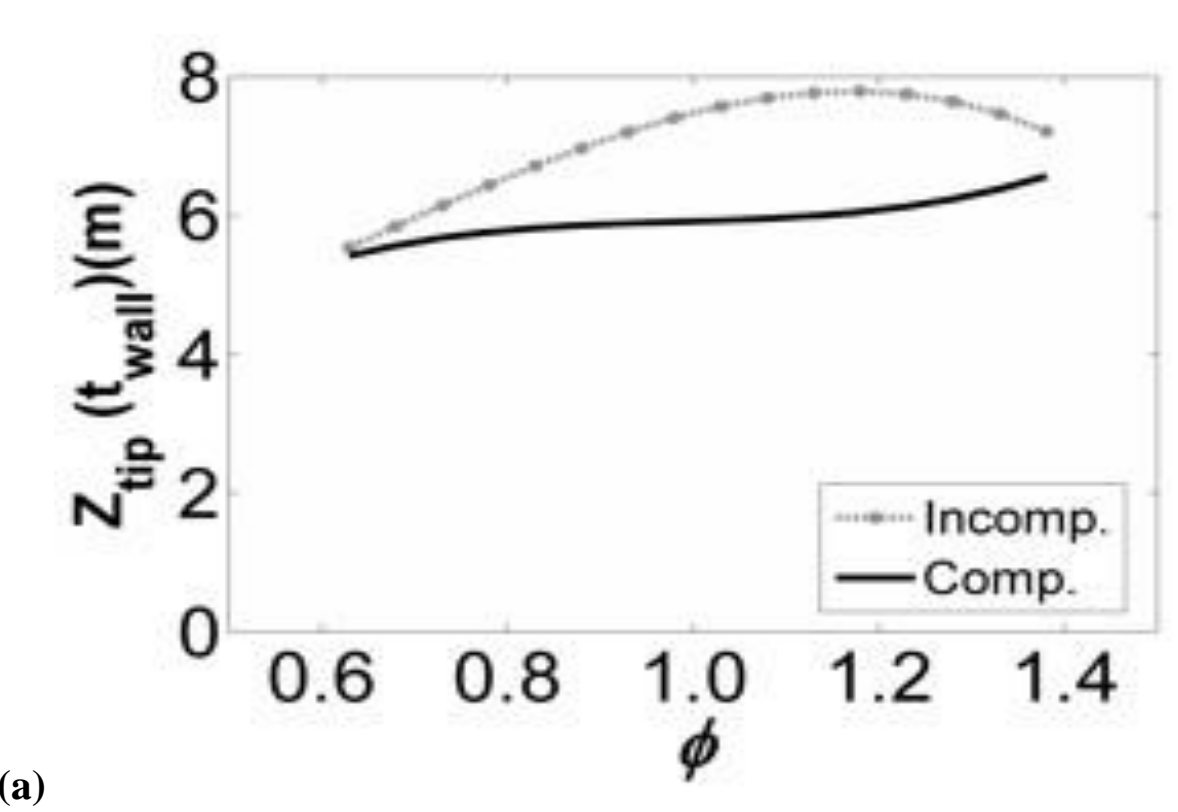

(a)

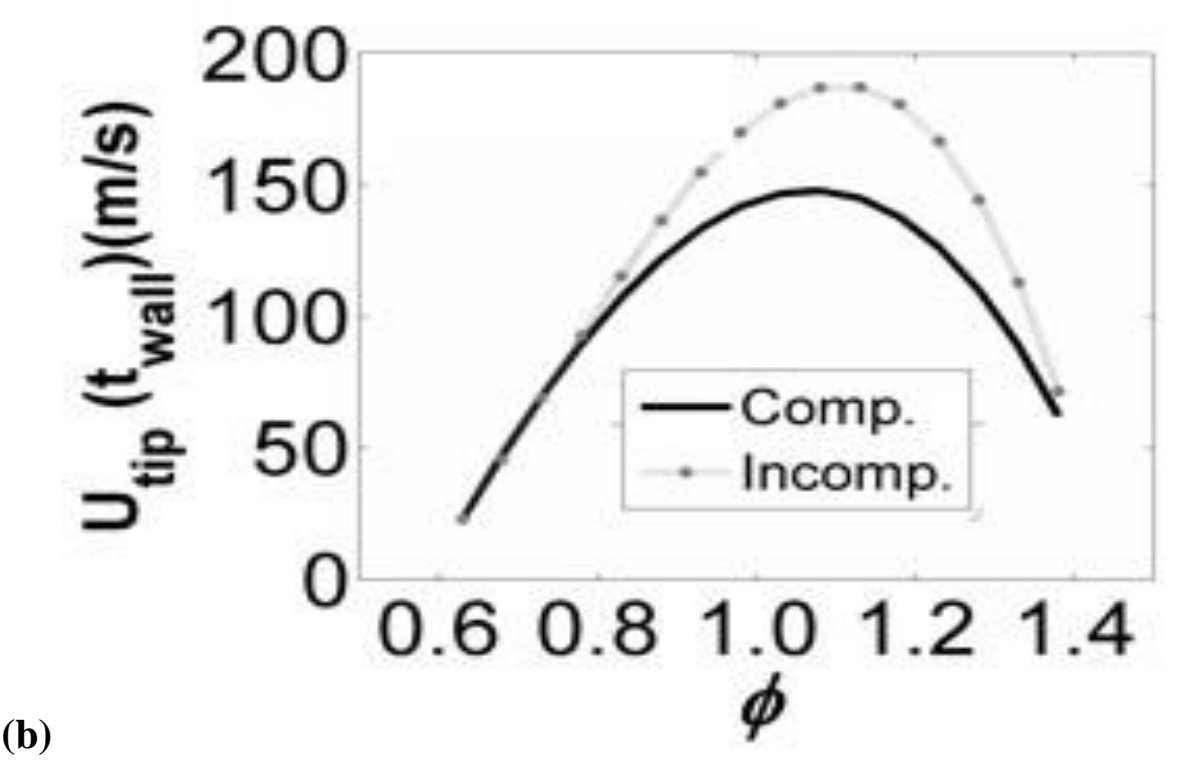

FIG. 7.2: Comparison of the incompressible (dashed) and compressible (solid) formulations: maximal coordinate $Z_{\text {tip }}\left(t_{\text {wall }}\right)$ (a) and velocity $U_{\text {tip }}\left(t_{\text {wall }}\right)(b)$, attained by a methane-air flame tip during the finger flame acceleration, versus the equivalence ratio $\phi$.

\section{EXTENSION TO DUSTY-GASEOUS COMBUSTION}

We next extend the analysis to dusty-gaseous combustion, since the presence of dust often plays a key role for the fire safety in coal mines [23,26-28]. In particular, combustible (say, coal) dust may spark a flame, promote its acceleration and even trigger DDT. On the other hand, inert dust 
particles (say, sand) may appear a "remedy" to prevent/mitigate a fire. The laminar flame velocity may either increase or decrease in the presence of dust. On the one hand, it is promoted by the effect of volatiles released from coal particles through the gaseous mixture, which appears an additional fuel source for the combustion process. On the other hand, dust particles gain heat from the flame during the devolatilization process, thereby acting as a heat sink [28]. Due to absorption of energy by the inert dust particles the energy available for the continual of the combustion process is reduced. This results in lowering of the burning .Historically, dust explosions has been very hazardous and has globally claimed thousands of lives. The Benxihu Colliery mine explosion disaster (April 26, 1942) was a very catastrophic incident which claimed over 1,500 lives. This over one third of the workers working during that day were killed and the mine was consequently shut for a year. Recently, the West Pharmaceutical Services explosion mine disaster in USA (09 February, 2003) resulted in the death of over 200 miners. Explosion in mines occur primarily due to the presence of combustible methane in the coal mine. The heat generated during the combustion of methane causes the temperature of the air to rise. This raise in temperature leads to the expansion of air, building up pressure in the mine. This leads to the air ahead of the combustion zone to compress and a shock wave is created. The coal dust particles is relatively difficult to ignite compared to methane, however the heat associated with the combustion of coal dust is very higher compared to methane. The higher energy involved with the combustion of coal dust leads to mining explosion. However, the dust explosion has been rarely studied in combustion literature and is one of the main focus of our work.

\subsection{Combustible Dust}

The Seshadri formulation [28] gave a relation between the laminar flame speed and the flame temperature $\left(T_{f}\right)$ is given as 


$$
S_{d, L}=\frac{1}{\overline{Z e}} \sqrt{\frac{2 B k}{\rho_{u} C_{T}} \exp \left(\begin{array}{c}
E \\
\left.\mid R_{u} T_{f}\right)
\end{array}\right.},
$$

where $Z e$ is the Zeldovich number and $E_{a}$ is the activation energy. The laminar flame speed is seen to increase with the flame temperature $\left(T_{f}\right)$. The characteristic Zeldovich number is denoted by the formulae

$$
Z e=\frac{E_{a}\left(T_{f}-T_{u}\right)}{R T_{f}^{2}} .
$$

The coal dust are suspended in the air of coal mines. These coal dusts have combustible volatilities in them. During accidental ignition in coal mines, the combustible volatilities evaporate from the coal dust. This results in an increase in local equivalence ratio of the fuel. The raise in equivalence ratio results in an increment in the fuel available for combustion and thereby increasing the flame temperature $\left(T_{f}\right)$, resulting in the increase in the laminar flame velocity. The equivalence ratio increase depends on the mass of the volatilities evaporated. The amount of volatilities depends on the devolatilization rate $\left(w_{v}^{\prime}\right)$, residence time $\left(t_{r}\right)$. The devolatilization rate $\left(w_{v}^{\prime}\right)$ rate is given by the power law with respect to temperature as below $w_{v}^{\prime}=A n_{s} 4 \pi r^{2} T_{s}^{N}$, where, $A$ and $N$ are known constants. The particle temperature $\left(T_{s}\right)$ is calculated as $T_{s}=\left(T_{v}+T_{b}\right) / 2$, The amount of the volatalities present at unit volume is given by, where $n_{s}=\left(c_{s} / \rho_{s}\right) / V_{\mathrm{s}}$, where $V_{\mathrm{s}}=4 \pi r_{s}^{3} / 3$ denotes the volume of the particle. Here $T_{v}$ is a temperature at which the devolatilization starts and is about the magnitude $600 \mathrm{~K}$. The residence time $\left(t_{r}\right)$ of a particle is defined as the time till which a particle remains until it moves into the 
combustion zone is estimated with Ref. [28] as 


$$
t_{r}=\frac{k_{u}}{\rho_{u} S_{L}^{2} C_{T}} .
$$

The total mass of the volatilities released per unit volume is $w=w^{\prime} t$, with the mass of gaseous

fuel released per unit volume $M^{m}=M^{m}+w$. Hence, the increase in mass of the fuel is due of fuel $\quad \mathrm{CH}_{4} \quad v$

the presence of volatilities. The $M_{C H_{4}}^{m}$ is the mass of methane per unit volume. The increased

equivalence ratio is then given by

$$
\phi_{s}=17.2\left(\frac{M_{f u e l}^{m}}{M_{\text {air }}^{m}}\right)_{a c t} \text {. }
$$

The coefficient 17.2 in Eq. (8.4) comes from the ratio of the methane mass to the air mass when $\phi=1$. The total heat energy released during combustion is equal to the sum of energy released during combustion of methane and by the coal dust volatilities. Hence, the total heat capacity is given by the formula

$$
C=C+C \bar{s}_{T}{\overline{3 \rho r_{s}^{3} \rho_{s}}}^{s} .
$$

Due to the increase in the local equivalence ratio, the flame temperature $\left(T_{f}^{\prime}\right)$ increases which is used in the Seshadri formulation [28]. The flame temperature is calculated to determine the laminar flame speed $\left(S_{L}^{\prime}\right)$

$$
\begin{aligned}
& \left\lceil\quad \begin{array}{lllll} 
& 2
\end{array}\right]^{1 / 2} \quad g \quad \underline{1} \quad E\left(T^{\prime}-T\right) \\
& S^{\prime}=\left|\frac{2 B k_{u} \varepsilon}{\exp }\right|-\frac{E}{R T}|| \quad, \quad \rho_{u}=1.135 \_ \text {_ }, \quad \varepsilon=Z_{Z}, \quad Z_{e}={\underline{R T_{u}^{\prime 2}}}^{.} \\
& \left.L \quad\left\lfloor\begin{array}{lll}
\rho_{u} C_{p} & \text { " }
\end{array}\right)\right\rfloor \quad c m \quad e \quad f
\end{aligned}
$$




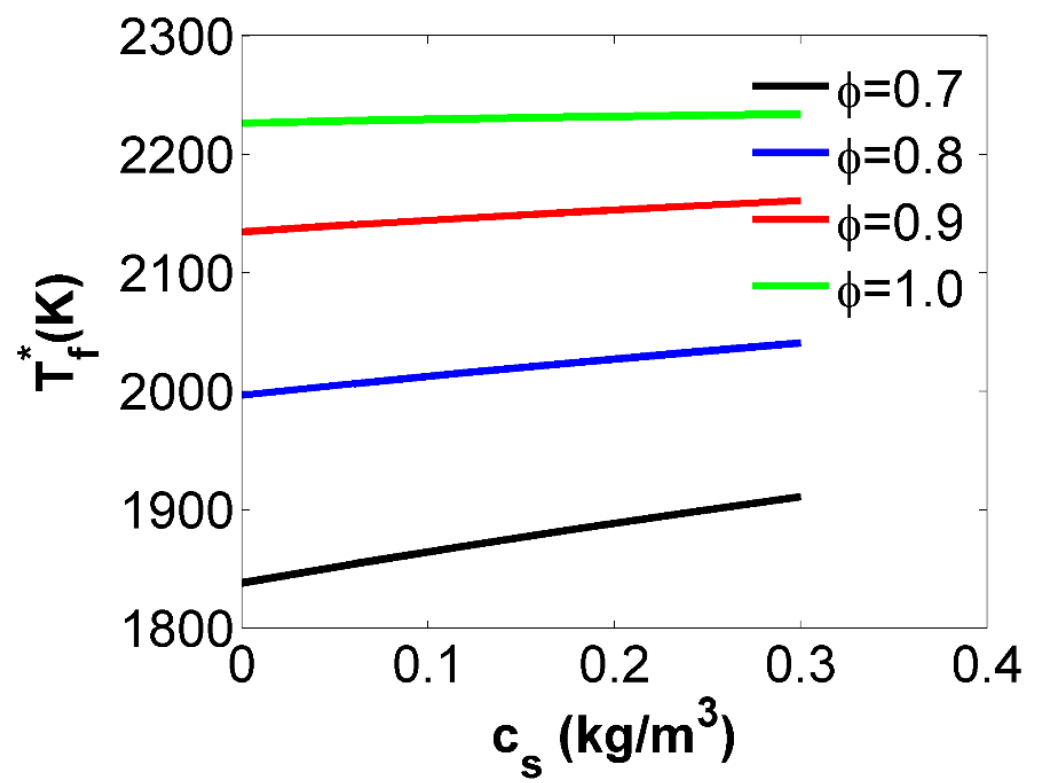

Fig. 8.1: The modified flame temperature (for methane air with combustible particles) vs the equivalence ratio at particle size of $75 \mu \mathrm{m}$.

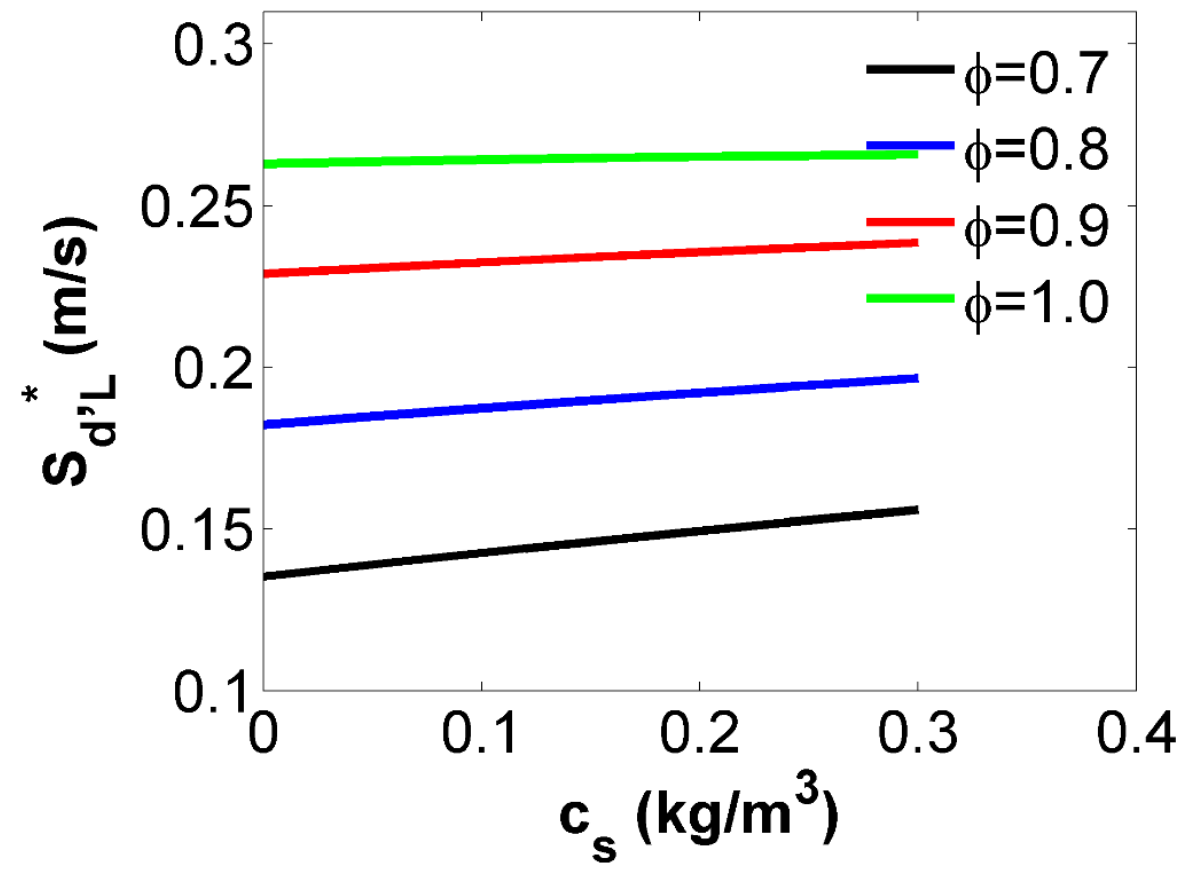

Fig. 8.2: The modified flame speed (for methane air with combustible particles) vs the equivalence ratio for the particle size $75 \mu \mathrm{m}$. 


\begin{tabular}{|llll|}
\hline $\mathrm{B}(1 / \mathrm{mols})$ & $3.5 \times 10^{6}$ & $\rho_{u}\left(\mathrm{~kg} / \mathrm{m}^{3}\right)$ & 1.135 \\
$\mathrm{k}_{u}(\mathrm{~kJ} / \mathrm{msK})$ & $0.52 \times 10^{-4}$ & $\rho_{s}\left(\mathrm{~kg} / \mathrm{m}^{3}\right)$ & 1000 \\
$\mathrm{E}(\mathrm{kJ} / \mathrm{mol})$ & 88.8 & $\mathrm{C}_{p}(\mathrm{~kJ} / \mathrm{kg} \cdot \mathrm{K})$ & 2.22 \\
$\mathrm{R}_{u}(\mathrm{~kJ} / \mathrm{mol} . \mathrm{K})$ & $8.314 \times 10^{-3}$ & $\mathrm{C}_{s}(\mathrm{~kJ} / \mathrm{kg} \cdot \mathrm{K})$ & 1.26 \\
\hline
\end{tabular}

Table 8.2: Some physical parameters used in the study [22]

The volatilities released during the combustion of inert particles result in the increase in the flame velocity. Since the laminar flame speed $\left(S_{L}\right)$ changes to $\left(S_{d, L}^{*}\right)$ there is a change observed in properties such as the coefficient of DL, time taken to reach the wall and skirt. Since, the combustible particles increase the burning rate $S^{*}{ }_{,}>S$.

$$
\text { d } \quad L
$$

\subsection{Inert Dust}

Non-combustible particles suspended in the air of coal mines are called inert particles. Since they don't combust, unlike the previous combustible case there is no energy produced by them. However, the chemical energy released during combustion process is used to increase the temperature of the sand particles. These inert particles having higher temperature heat capacity, requires more heat to raise its temperature as compared to the air-fuel mixture. In a case where air-fuel mixture of equivalence ratio $(\phi)$ combusts, we have

$$
\phi C H+2(O+3.76 N) \Rightarrow \phi C O+2 \phi H O+7.52 N+4(1-\phi) O .
$$

A mole of the air-fuel mixture with 7.52 moles of $N_{2}$ reacts with 2 moles of $O_{2}$ to form the

products. Hence, for a given equivalence ratio, the heat release rate from the air fuel mixture is given by

$$
\left.Q=\left[(T-T){ }_{b} \sum_{p}^{C \cdot n}\right]_{\text {product }}\right]_{9.52}^{n_{\text {air }}} \lambda .
$$


Here, $\lambda$ and $n_{\text {product }}$ are the stoichiometric ratio and the number of moles of the burning products. 


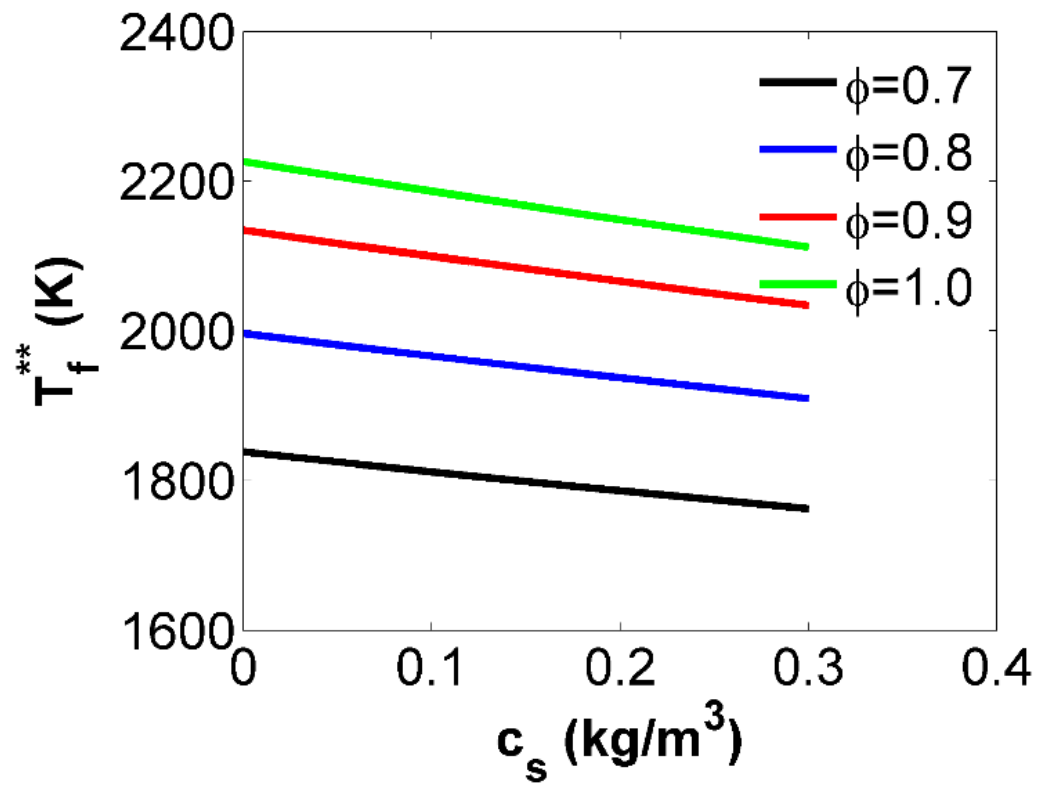

FIG. 8.3: The modified flame temperature (due to inert particles) vs the concentration of inert particles.

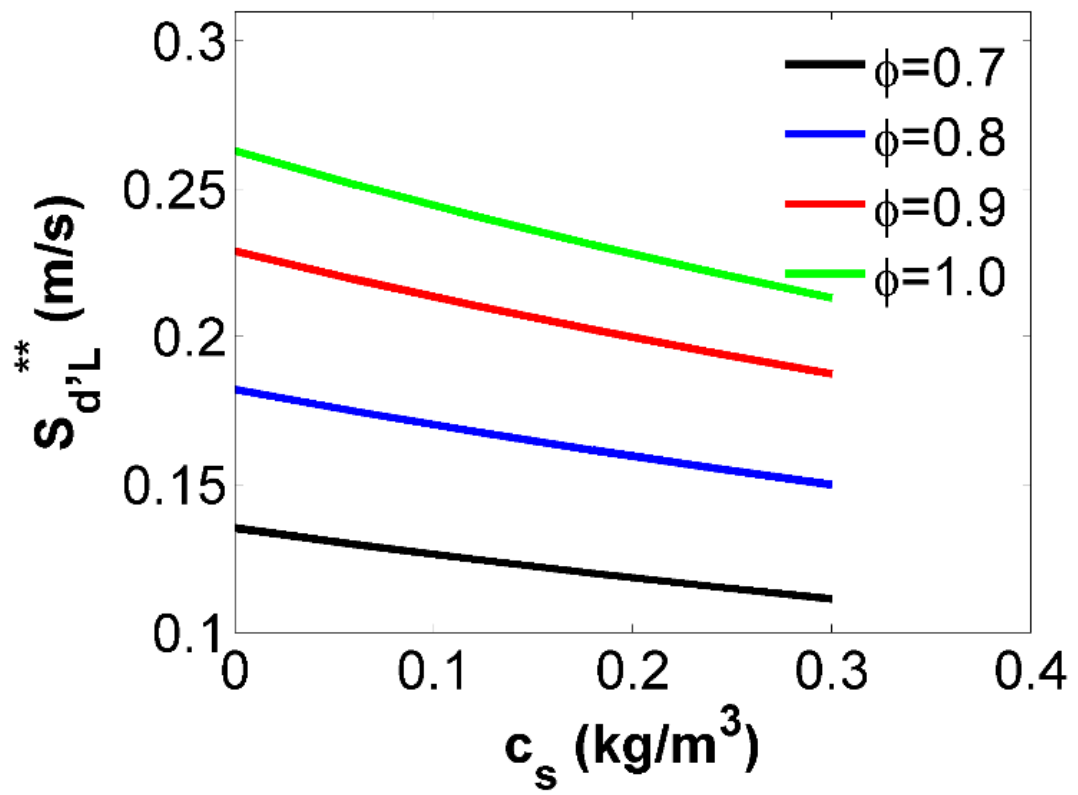

FIG. 8.4: The modified planar flame speed (due to inert particles) vs the concentration of inert particles

The modified flame temperature $T_{f}^{* *}$ is given by

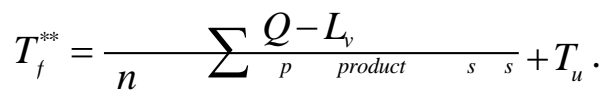

\subsection{2}


$\underset{\text { air }}{-\lambda} C \cdot n+n^{\prime} C$ 
Unlike combustible particles which have a positive effect on the planar flame speed, the inert particles reduce the planar flame speed. The inert particles act as a heat sink, reducing the planar flame speed. The modified planar flame speed due to inert particles is given by $S_{L}^{* *}$.

\subsection{Combination of Combustible and Inert Dust}

In fact, both combustible and inert particles may be present. There is a phenomenon where there is both heat addition due to combustibles and the heat sink effect due to inert particles. The consequent flame temperature is given by the average of both modified flame temperature due to only combustible particles $\left(T_{f}^{*}\right)$ and modified flame temperature due to only due to inert particles $\left(T_{f}^{* * *}\right), T_{f}^{* * * * *}=\left(T_{f}^{*}+T_{f}^{* * *}\right) / 2$. Due to the heat sink effect of the inert particle and the effective equivalence increase due to combustibles. Consequently, the effective modified flame temperature is found to be intermediate to both inert and combustible particles, for a given equivalence ratio and concentration. The planar flame is observed to follow the same trend.

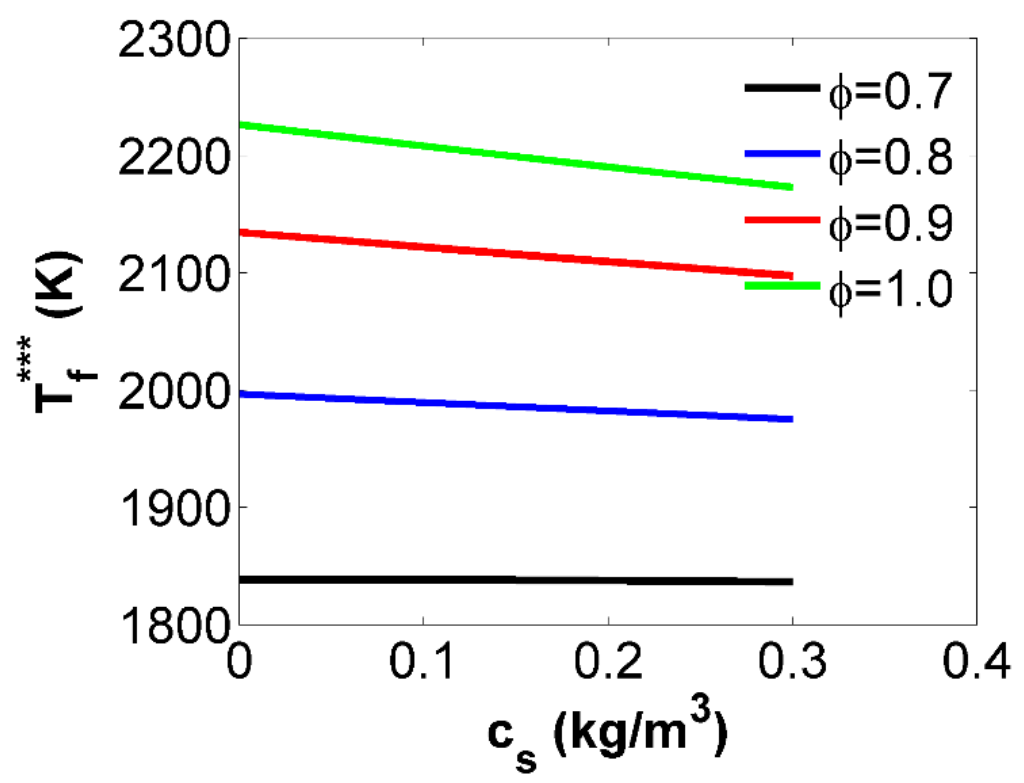

Fig. 8.5: The modified flame temperature (due to combined of both particles) vs the concentration of combined particles 


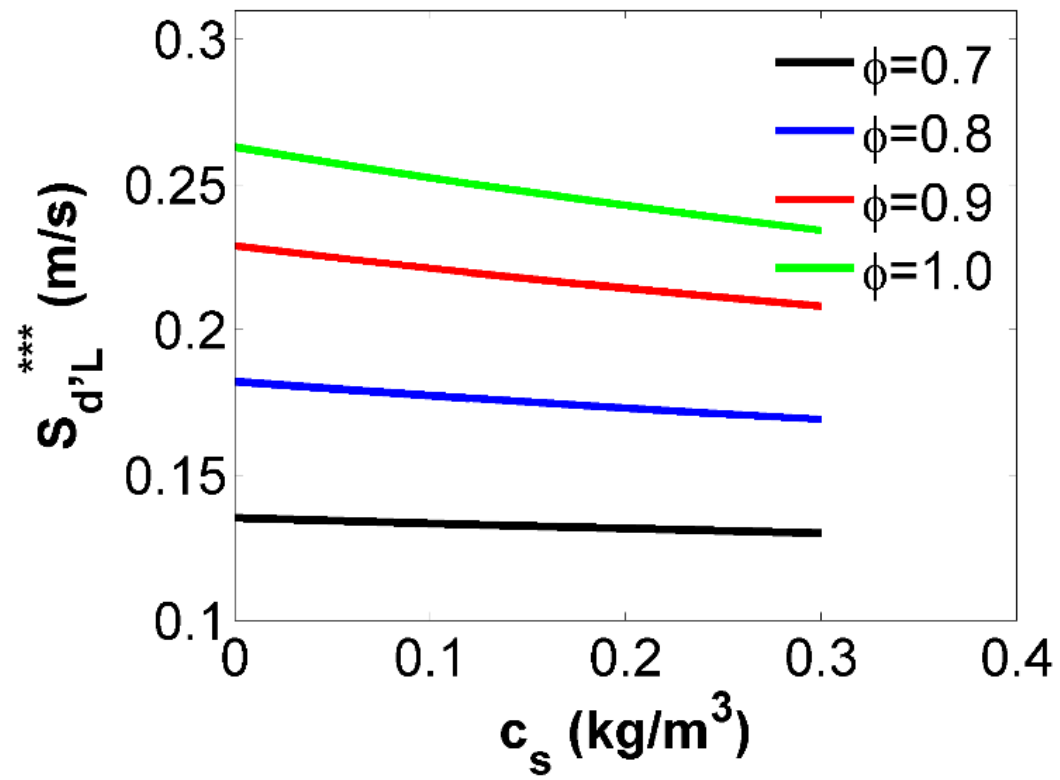

Fig. 8.6: The modified planar flame speed (due to combined of both particles) vs the concentration of combined particles.

\section{RESULTS and DISCUSSION (Dusty-Gaseous Environment)}

Figure 9.1 demonstrates the effect of gas compression on flame acceleration in the presence of combustible dust. Specifically, small $\left(r_{s}=10 \mu \mathrm{m}\right)$ and relatively larger $\left(r_{s}=75 \mu \mathrm{m}\right)$ dust particles are considered, $\phi=0.7$ and $c=120 \mathrm{~g} / \mathrm{cm}^{3}$ in both cases. The event of no particles is also presented and compared. Combustible dust promotes the flame velocity; and the smaller the particles the stronger acceleration is. According to Fig. 9.1a, the relative reduction in $Z_{\text {tip }}\left(t_{\text {wall }}\right)$ due to gas compression is $8 \%$ for $r_{s}=10 \mu \mathrm{m}, 5 \%$ for $r_{s}=75 \mu \mathrm{m}$ and $4 \%$ for the event of no dust. As for the flame tip velocity, Fig. 9.1b, the relative reduction in $U_{\text {tip }}\left(t_{\text {wall }}\right)$ constitutes $19 \%$ for $r_{s}=10 \mu \mathrm{m}, 12 \%$ for $r_{s}=75 \mu \mathrm{m}$ and $11 \%$ for no dust. Consequently, gas compression moderates methane-air-dust flame acceleration, and the effect appears even stronger than that for 
gaseous combustion. 


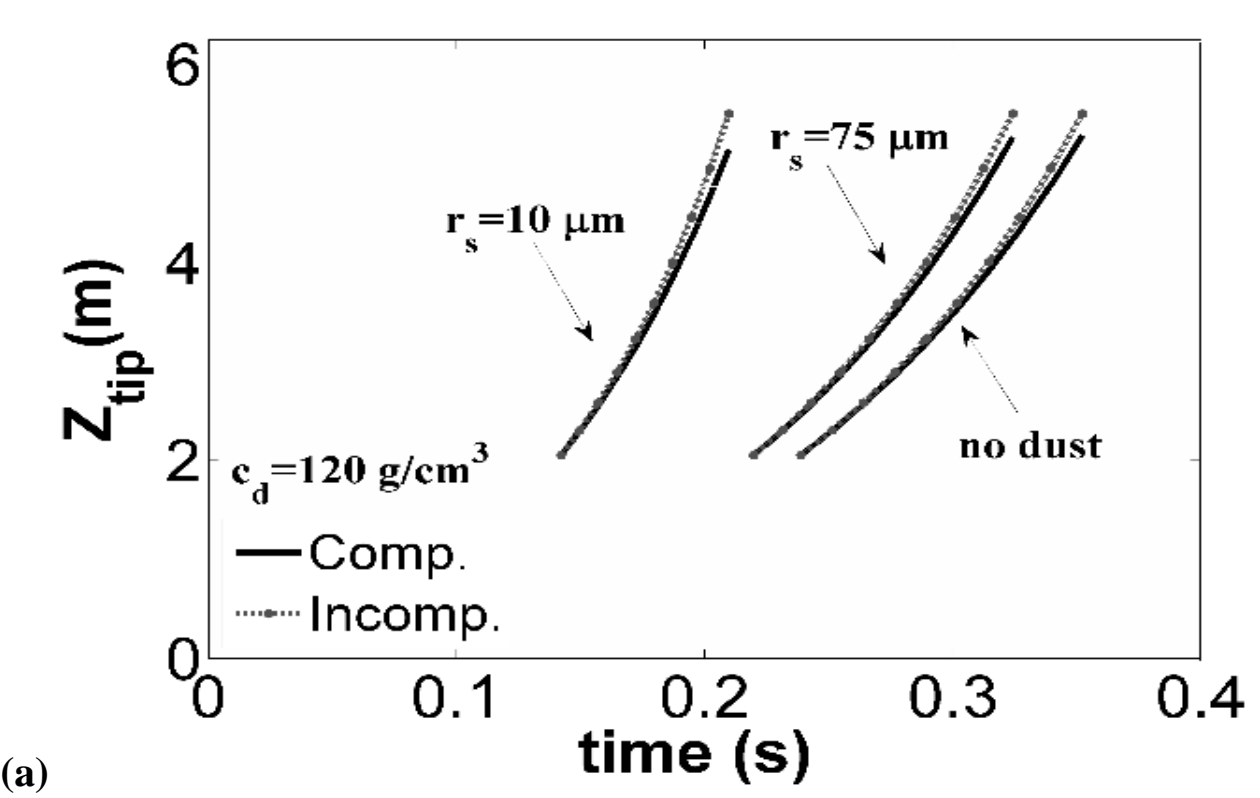

(a)

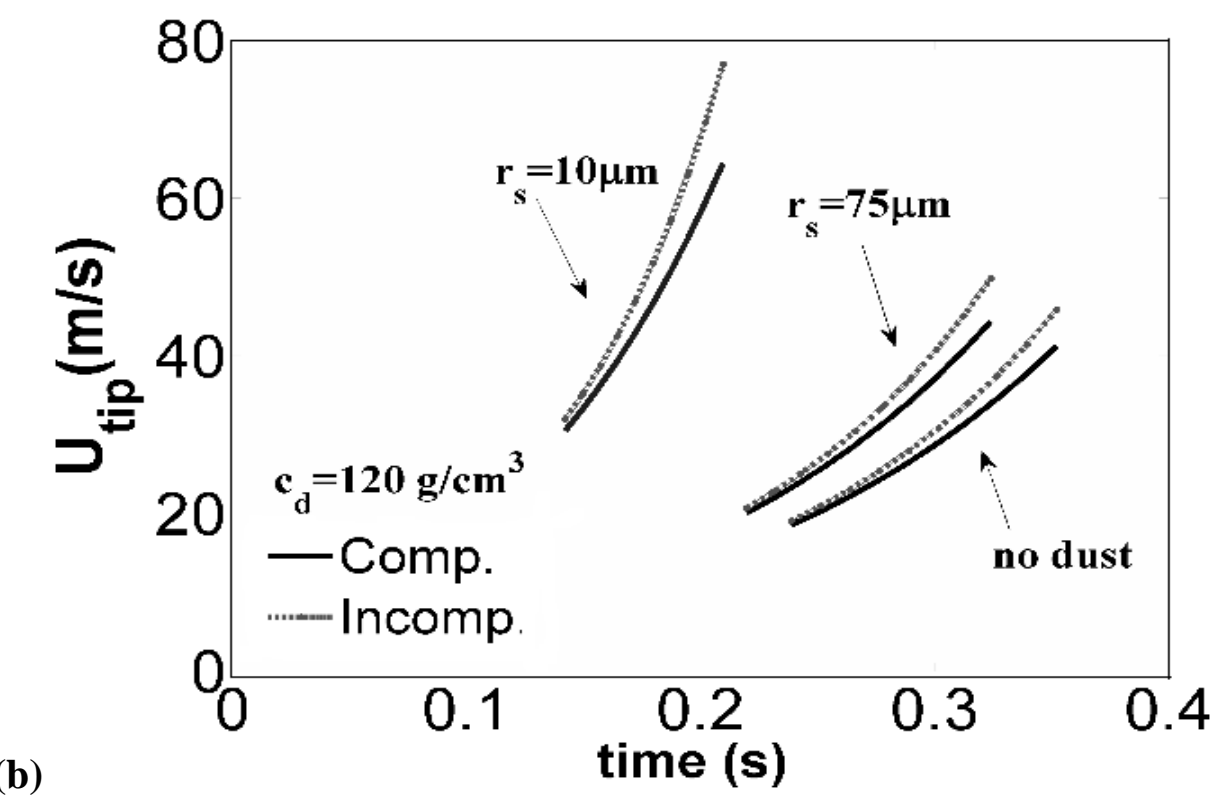

FIG. 9.1: Comparison of the incompressible (dashed) and compressible (solid) formulations: evolution of the flame tip position $Z_{t i p}(a)$ and its velocity $U_{t i p}(b)$ for methane-air flames of equivalence ratio $\phi=0.7$ in the presence of combustible dust of concentration $c_{d}=120 \mathrm{~g} / \mathrm{cm}^{3}$ and mean particle radii

$$
r_{s}=10 \mu m, 75 \mu m \text {. }
$$




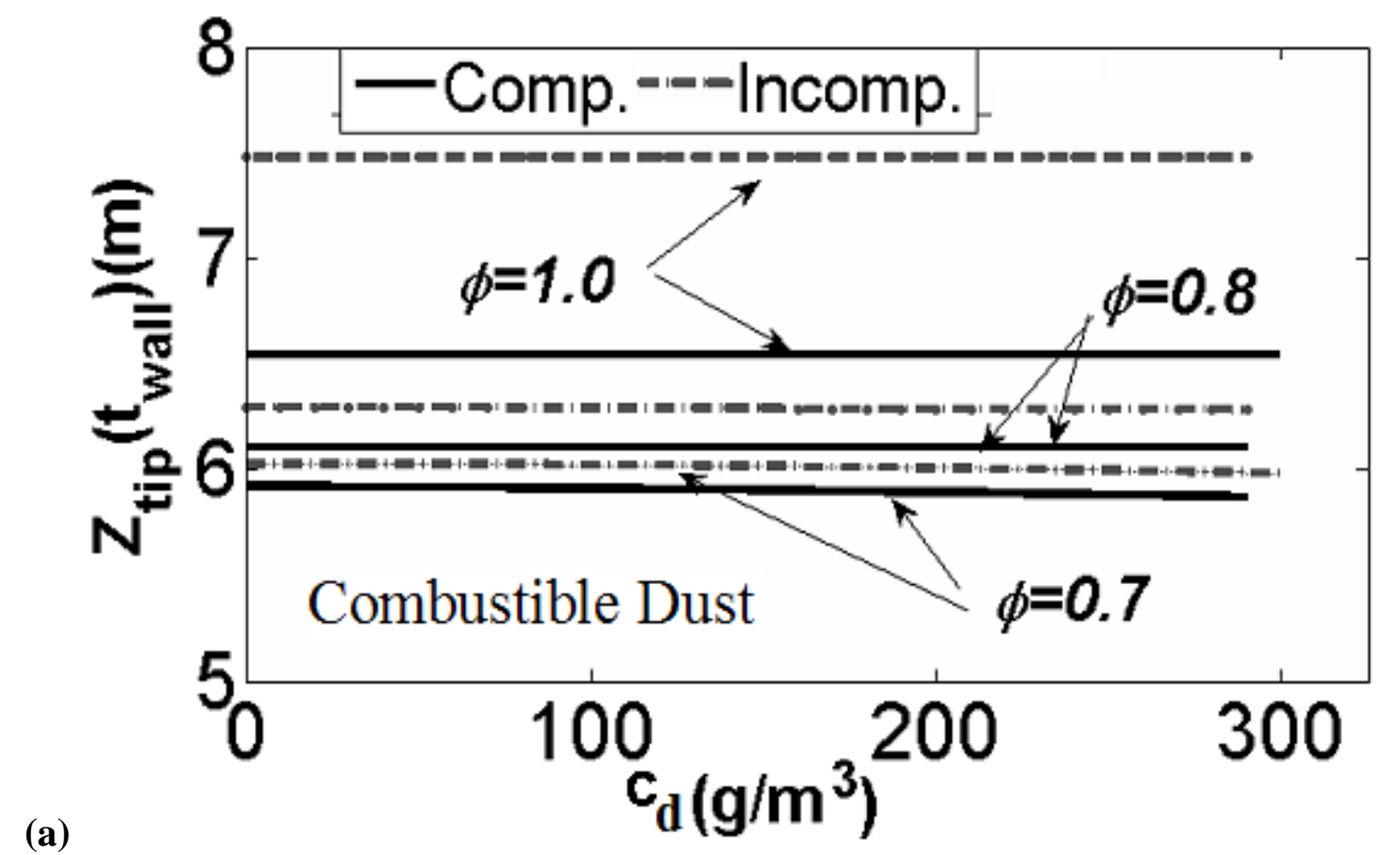

(a)

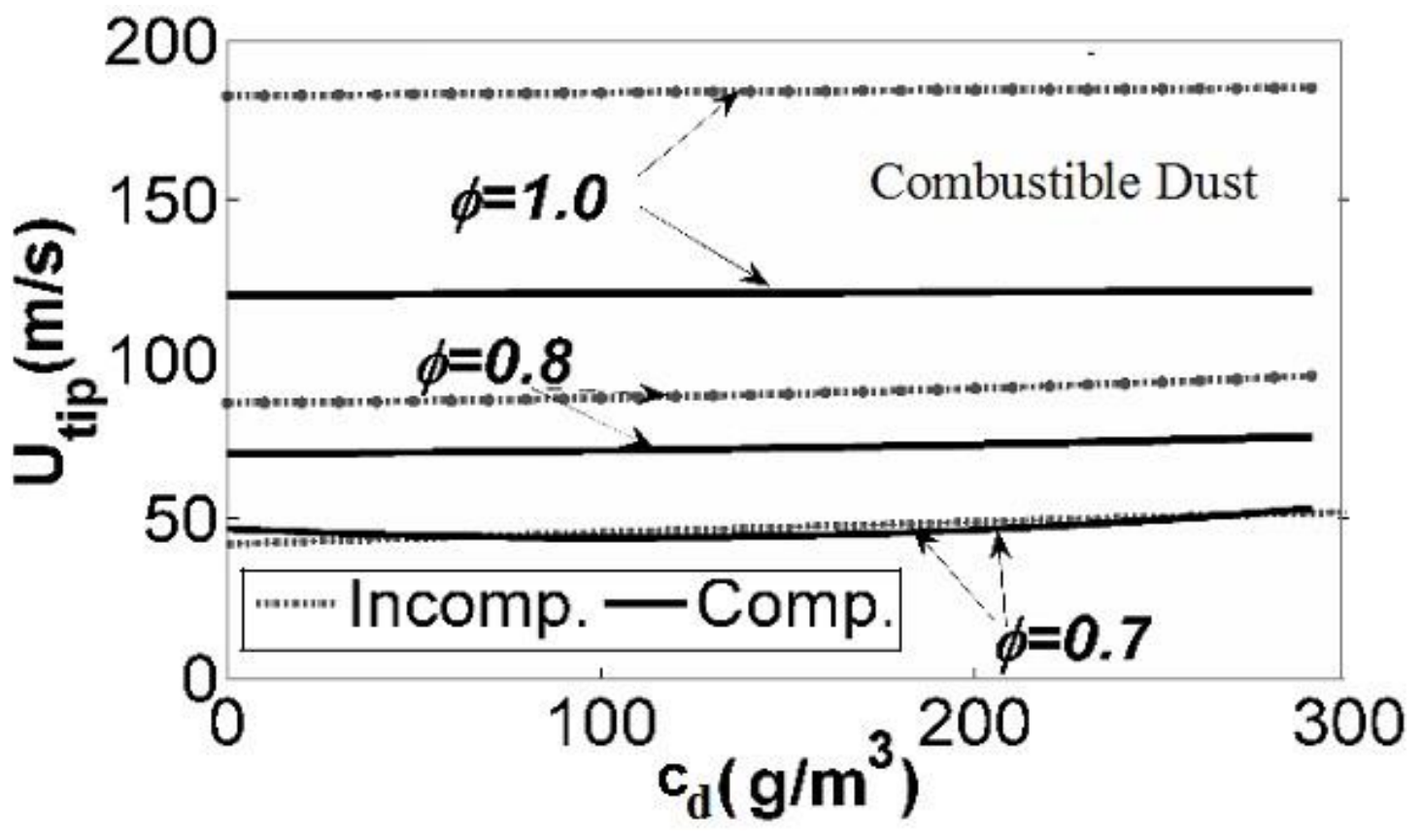




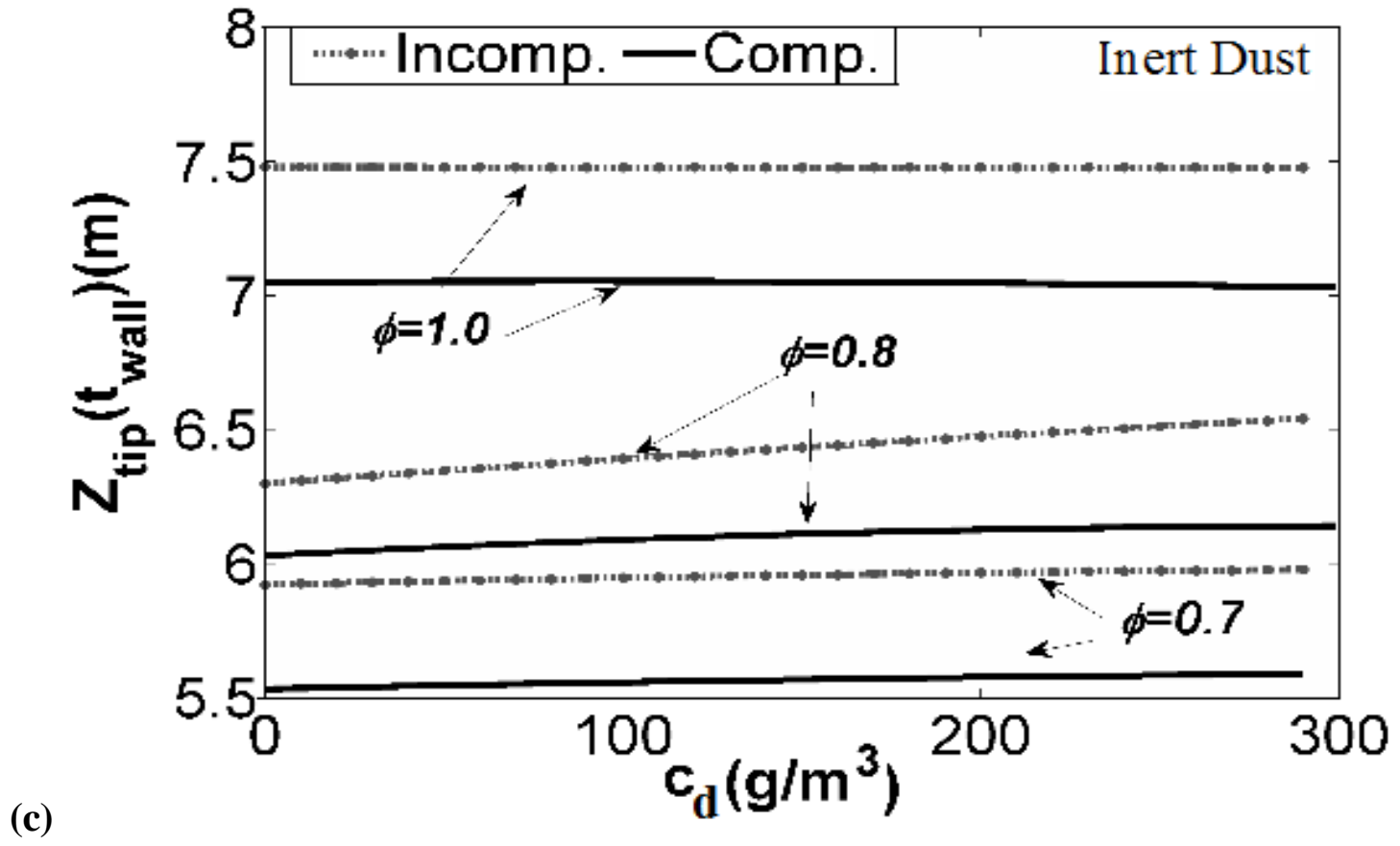

(c)

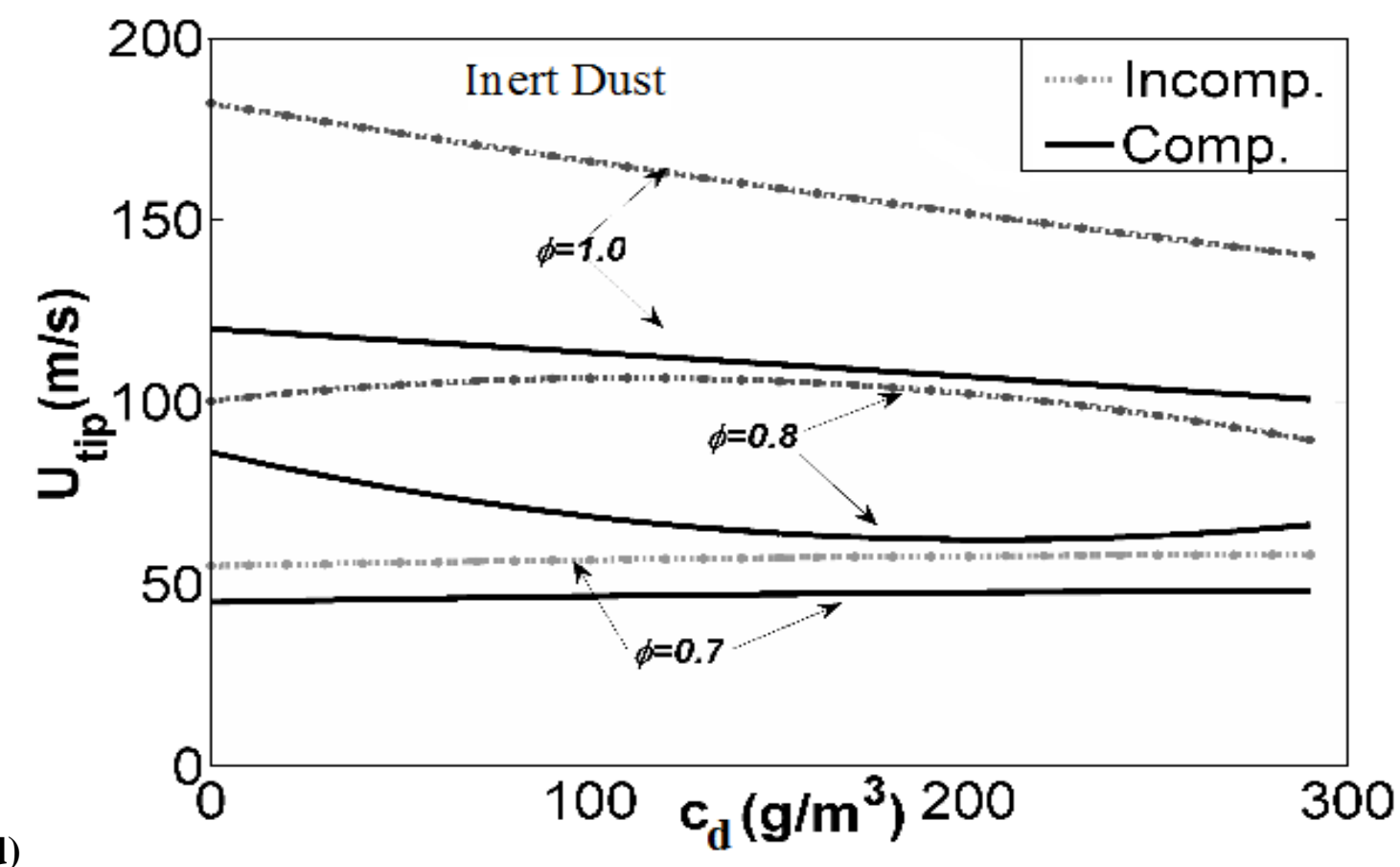

FIG. 9.2: Comparison of the incompressible (dashed) and compressible (solid) formulations: maximal coordinate $Z_{\text {tip }}\left(t_{\text {wall }}\right)(\boldsymbol{a}, \boldsymbol{c})$ and velocity $U_{\text {tip }}\left(t_{\text {wall }}\right)(\boldsymbol{b}, \boldsymbol{d})$, attained by the tip of methane-air-dust flames of various equivalence ratios $\phi=0.7,0.8,1.0$ during the finger acceleration, versus the concentration $c_{d}$ of combustible $(a, b)$ and inert $(c, d)$ dust of particle radius $r_{s}=75 \mu \mathrm{m}$. 


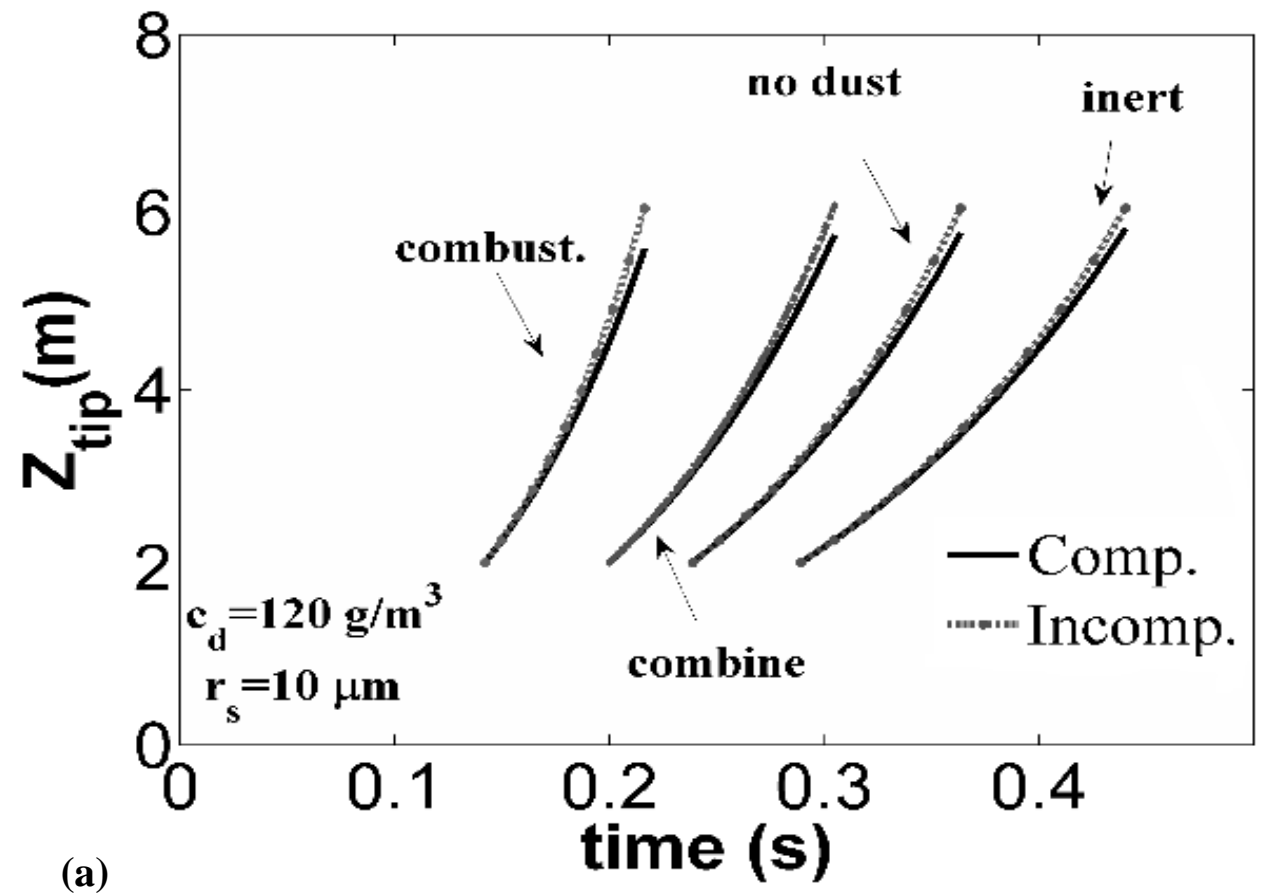

(b)

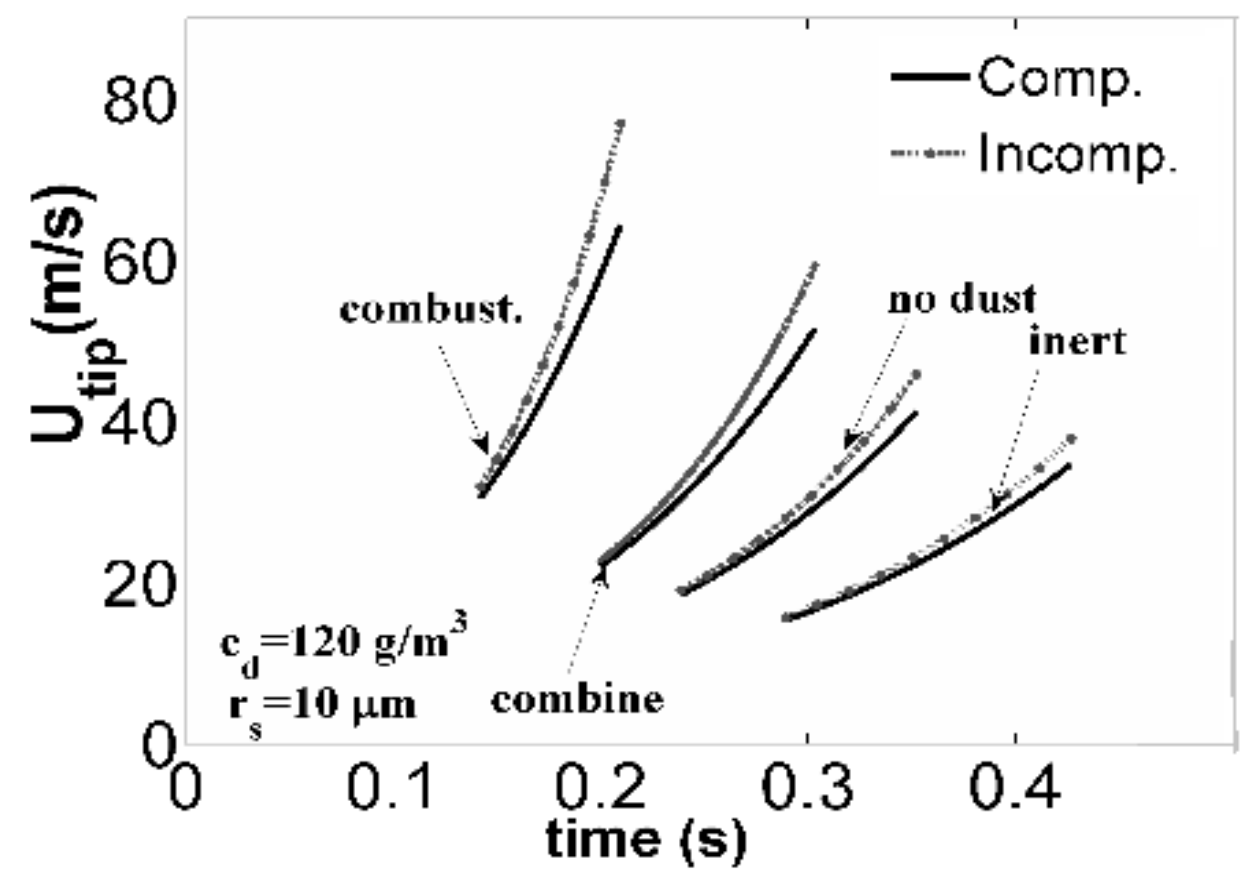

FIG. 9.3: Comparison of incompressible (dashed) and compressible (solid) formulations: evolution of the flame tip position $Z_{\text {tip }}\left(\right.$ a) and its velocity $U_{\text {tip }}$ (b) for methane-air flames of equivalence ratio $\phi=0.7$ for no dust as well as in the presence of combustible and/or inert dust of concentration $c_{d}=120 \mathrm{~g} / \mathrm{cm}^{3}$ and mean particle radius $r_{s}=10 \mu \mathrm{m}$. 
The dependences of $Z_{\text {tip }}\left(t_{\text {wall }}\right)$ and $U_{\text {tip }}\left(t_{\text {wall }}\right)$ versus the particle concentration are presented in Fig. 9.2 for $r_{s}=75 \mu m$ and various $\phi$. Here, Fig. 9.2 (a,b) are devoted to combustible dust, while inert dust is shown in Figs. 9.2 (c,d). In is seen that unlike the particle size, the concentration influences the flame dynamics much weaker: the effect is really minor for combustible dust, and it is moderate for inert particles.

Finally, the flame evolutions in the situations of no dust, combustible dust, inert dust, and their combination are compared in Fig. 9.3 for $\phi=0.7, c_{d}=120 \mathrm{~g} / \mathrm{cm}^{3}$, and $r_{s}=10 \mu \mathrm{m}$. It is observed

that both combustible and inert particles provide noticeable deviations from the no-dust curves by promoting/moderating flame acceleration, respectively. When both combustible and inert dust present in the mixture, their impacts oppose each other such that their net effect resembles that of no dust. Still, the relative effect of combustible dust exceeds that of inert one. The influence of gas compression is also seen. Qualitatively, Fig. 9.3a shows the relative reduction in $Z_{\text {tip }}\left(t_{\text {wall }}\right)$ due to gas compression to be $4 \%$ for no dust, also $4 \%$ for inert dust, $8 \%$ for combustible dust and $6 \%$ for their combination. As for the flame tip velocity, Fig. 9.3b, gas compression provides the relative reduction in $U_{\text {tip }}\left(t_{\text {wall }}\right)$ of $11 \%$ for no dust, of $10 \%$ for inert particles, of $18 \%$ for combustible particles, and of $14 \%$ for their combination.

\section{CONCLUSIONS}

In this work, the incompressible theory of methane-air/dust flame acceleration in a mining passage [22] is validated by incorporating the effect of gas compression into the analysis. It is shown that gas compression moderates flame acceleration, and its impact depends on various 
thermal-chemical parameters. The relative role of gas compression (as compared to the 
predictions [22]) is quantified for a variety of parameters such as $\phi, r_{s}, c_{d}$, and it appeared to be stronger for dusty-gaseous environments as compared to purely gaseous combustion.

As a result, the intrinsic accuracy of the formulation [22] for a given set of parameters is identified. While the effect of compressibility is minor (3-5\% reduction) for lean and rich flames, thereby justifying the incompressible formulation in that case, it is significant (up to $22 \%$ reduction) for near-stoichiometric methane-air combustion. Furthermore, in contrast to the incompressible prediction, the solution to Eq. (5.24) for $Z_{t i p}\left(t_{\text {wall }}\right)$ demonstrates a qualitatively

different, monotonic dependence on $\phi$, Fig. 7.2a, thereby yielding that gas compression may actually control acceleration for reach flames, $\phi \sim 1.1$.

A more accurate predictive scenario was obtained for fire explosions in gaseous and dusty-gas mining environments by taking into account compressibility. Since, all liquids are compressible, we can get more accuracy by accounting in for compressibility. The effect of compressibility was maximum for near-stoichiometric air fuel mixtures and minimal for lean mixtures.

Through the study of dusty particles, it was clearly seen that inert particles could be used to mitigate mine fires. Additionally, the study of flame propagation in a dusty fire scenario reveled that compressibility had the maximal impact in case of explosions in mines having combustible dusts and least for mining scenarios with inert dust particles. This effect is due to the local equivalence ratio increase and heat sink effect of the combustible and inert particles respectively. 


\section{References}

1. NPTEL Lecture Series, "Fundamentals of Combustion", http://nptel.iitg.ernet.in/

2. V. Akkerman, Turbulent Burning, Flame Acceleration, Explosion Triggering, $\mathrm{PhD}$ thesis, Umea, Sweden, 2007, https://www.diva-portal.org/smash/get/diva2:140054/FULLTEXT01.pdf

3. Michael A. Liberman,'Introduction to Physics and Chemistry of Combustion- Explosion, Flame, Detonation", Springer, 2008.

4. P. Clavin, Dynamics of Gaseous Combustion Waves, Princeton Summer School, 2015.

5. C. Clanet, G. Searby, On the Tulip Flame Phenomenon, Combust. Flame 105 (1996) 225.

6. V. Bychkov, V. Akkerman, G. Fru, A. Petchenko, L.-E. Eriksson, Flame Acceleration in the Early Stages of Burning in Tubes, Combust. Flame 150 (2007) 263.

7. D. Valiev, V. Akkerman, M. Kuznetsov, L.-E. Eriksson, C.K. Law, V. Bychkov, Influence of Gas Compression on Flame Acceleration in the Early Stage of Burning in Tubes, Combust. Flame 160 (2013) 97.

8. K.I. Shelkin, Influence of the Wall Roughness on Initiation and Propagation of Detonation in Gases, Zh. Eksp. Teor. Fiz. 10 (1940) 823.

9. L. Kagan, G.I. Sivashinsky, The Transition from Deflagration to Detonation in Thin Channels, Combust. Flame 134 (2003) 389.

10. J.D Ott, E.S Oran, J.A Anderson, A Mechanism for Flame Acceleration in Narrow Tubes, AIAA Journal 41 (2003) 1391.

11. V. Bychkov, A. Petchenko, V. Akkerman, L.-E. Eriksson, Theory and Modeling of Accelerating Flames in Tubes, Phys. Rev. E 72 (2005) 046307.

12. V. Akkerman, V. Bychkov, A. Petchenko, L.-E. Eriksson, Accelerating Flames in Cylindrical Tubes with Nonslip at the Walls, Combust. Flame 145 (2006) 206.

13. V. Akkerman, C.K Law, V. Bychkov, L.-E Eriksson, Analysis of Flame Acceleration induced by Wall Friction in Open Tubes, Phys. Fluids 22 (2010) 053606.

14. D. Valiev, V. Bychkov, V. Akkerman, L.-E Eriksson, Different Stages of the Flame Acceleration from Slow Burning to Chapman-Jouguet Deflagration, Phys. Rev. E 80 (2009) 036317.

15. V. Bychkov, D. Valiev, L.-E. Eriksson, Physical Mechanism of Ultra-Fast Flame Acceleration. Phys. Rev. Lett. 101 (2008) 164501. 
16. D. Valiev, V. Bychkov, V. Akkerman, C.K. Law, L.-E. Eriksson, Flame acceleration in channels with obstacles in the deflagration-to-detonation transition, Combust. Flame 157 (2010) 1012.

17. K.L. Cashdollar, M.J. Sapko, E.S. Weiss, M.L. Harris, C.K. Man, S.P. Harteis, G.M. Green, Analysis of Post-Explosion Residues for Estimating Flame Travel During Coal Dust Deflagrations, Report of Investigations, NIOSH, Pittsburgh (2010) p. 9679.

18. K. Chatrathi, J.E. Going, B. Grandestaff, Dust Flame Propagation in Industrial Scale Piping - Part 1: Empirical Study in a Conveying Vessel-Pipeline System, Proc. Saf. Prog. 20 (2001) 286.

19. M. Bi, C. Dong, Y. Zhou, Propagation of Ethylene-Air Flames in Closed Cylindrical Vessels with Asymmetrical Ignition, Appl. Therm. Eng. 40 (2012) 337.

20. R.W. Houim, E.S. Oran, Formation and Evolution of Distorted Tulip Flames, J. Loss Prev. Process Ind. 36 (2015) 214.

21. X. Chen, Y. Zhang, Y. Zhang, Effect of $\mathrm{CH}_{4}$-Air Ratios on Gas Explosion Flame Microstructure and Propagation Behaviors, Energies 5 (2012) 4132.

22. V. Akkerman, S. Demir, S. Chalazgalla, A. S. Rangwala, V. Bychkov, Predictive Scenario for Premixed Methane-Air Flame in a Mining Passage, Combust. Flame, submitted.

23. S. Rockwell, A. Rangwala, Influence of Coal Dust on Premixed Turbulent Methane-Air Flames, Combust. Flame 160 (2013) 635.

24. V. Akkerman, C.K. Law, V. Bychkov, Self-Similar Accelerative Propagation of Expanding Wrinkled Flames and Explosion Triggering, Phys. Rev. E 83 (2011) 026305.

25. S.G. Davis, J. Quinard, G. Searby, Markstein Numbers in Counterflow, Methane- and Propane-Air Flames: A Computational Study", Combust. Flame 130 (2002) 123.

26. V. Akkerman, V. Bychkov, Turbulent Flame and the Darrieus-Landau Instability in a Three-Dimensional Flow, Combust. Theory Modelling 7 (2003) 767.

27. Y. Xie, V. Raghavan, A.S. Rangwala, Study of Interaction of Entrained Coal Dust Particles in Lean Methane-Air Premixed Flames, Combust. Flame 159 (2012) 2449.

28. K. Seshadri, A.L. Berlad, V. Tangirala, The Structure of Premixed Particle-Cloud Flames, Combust. Flame 89 (1992) 333. 
29. A.R. Calavay, S. Demir, A.S. Rangwala, V. Akkerman, Influence of Gas Compression on the Methane-Air-Dust Fire Scenario in a Mining Passage, Proceedings of the Combustion Institute - submitted, 